\title{
FROM THE GROUND UP: CHILDREN'S EXPERIENCES OF CONNECTING WITH NATURE THROUGH TECHNOLOGY
}

\author{
by \\ Michael Agam, BASc (Hons), University of Guelph-Humber, 2019 \\ An MRP \\ presented to Ryerson University \\ in partial fulfillment of the \\ requirements for the degree of \\ Master of Arts \\ in the program of \\ Early Childhood Studies
}

Toronto, Ontario, Canada, 2020

(C) Michael Agam, 2020 


\section{AUTHOR'S DECLARATION}

I hereby declare that I am the sole author of this MRP. This is a true copy of the MRP, including any required final revisions.

I authorize Ryerson University to lend this MRP to other institutions or individuals for the purpose of scholarly research

I further authorize Ryerson University to reproduce this MRP by photocopying or by other means, in total or in part, at the request of other institutions or individuals for the purpose of scholarly research.

I understand that my MRP may be made electronically available to the public. 


\begin{abstract}
From the Ground up: Children's Experiences of Connecting with Nature through Technology Master of Arts, 2020

Michael Agam

Early Childhood Studies, Ryerson University
\end{abstract}

The benefits of children engaging with and in nature have been well documented in past research. However, many children today are increasingly engaging with digital technologies. Interestingly, technologies have been suggested for children to engage with and explore nature, though little research includes the ideas and insights of young children. To fill this gap in research, this study utilized a secondary data analysis approach. Data ascertained from an ongoing project that explores children's engagement in ecological curriculum and research was used to examine how children use technology to explore nearby nature. Prevalent themes of this study acknowledge that many children have experiences with digital technologies, digital technologies supported children in their ecological and nature based research, and digital technologies supported children's connections with nature. The results of this study have implications for how educators can incorporate technology into their pedagogy and for future researchers who may explore this nature-technology discourse. 


\section{ACKNOWLEDGEMENTS}

I give my utmost and sincere thanks to my supervisor, Dr. Susan Jagger who supported me with guidance throughout this academic journey. This paper would have been impossible to write without you.

I also give thanks to those I call family and friends, all of whom I am extremely grateful for. Your presence in my life is inspiring and I shall continue to cherish your companionship until the end of time. 


\section{DEDICATION}

I dedicate this work to the living and nonliving beings of the past, present, and future. 


\section{TABLE OF CONTENTS}

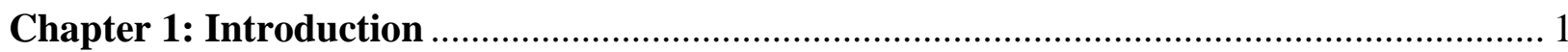

Chapter 2: Literature Review ................................................................................. 7

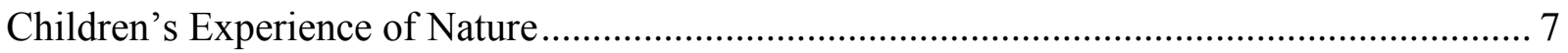

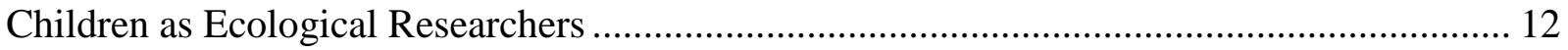

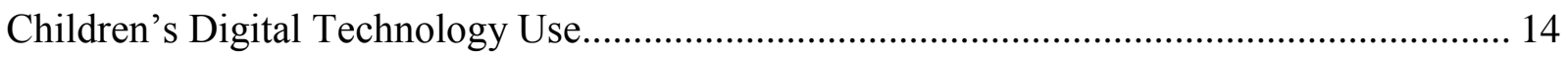

Children's Digital Technology Use in Early Years and School Environments ....................... 16

Children's Use of Digital Technology to Explore and Connect to Nature ............................ 18

Children's Utilization of Digital Technology to Conduct Ecological Research .................... 20

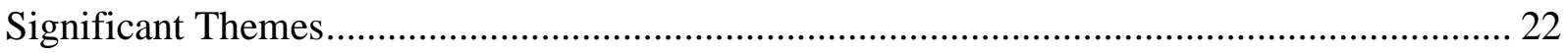

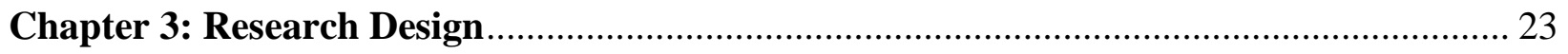

Primary Research Project: Empowering Young Citizens .............................................. 23

Primary Research Project: Theoretical Framework.................................................... 23

Primary Research Project: Setting and Participants .................................................. 25

Primary Research Project: Approach .................................................................. 26

Primary Research Project - Research Process ........................................................ 27

Research Design of the Secondary Data Analysis ........................................................... 29

Research Design-Secondary Data Analysis ......................................................... 30

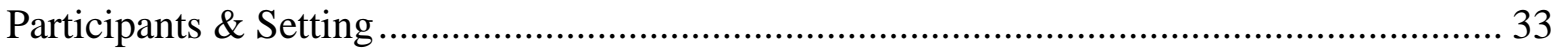

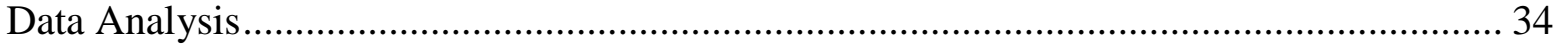




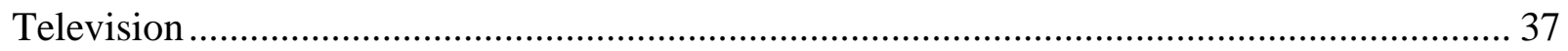

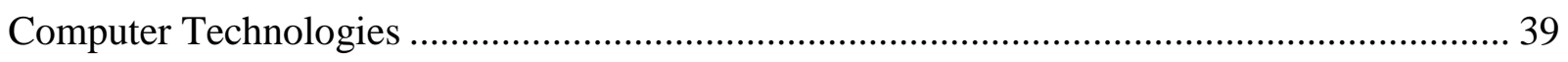

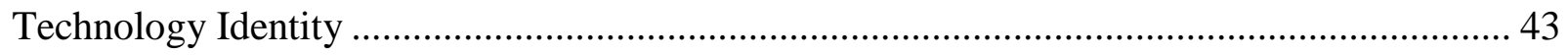

Chapter 5: Children, Technology, and Ecological-based Research ................................. 45

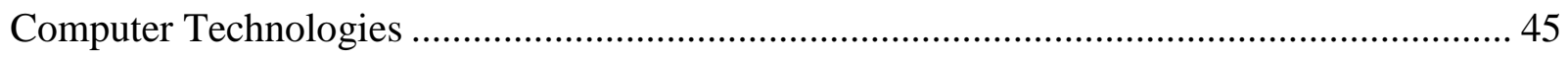

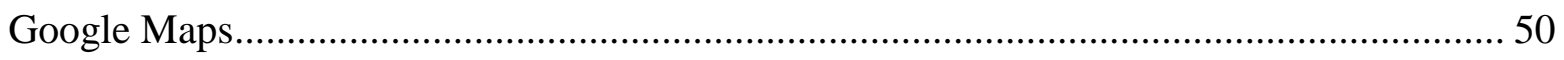

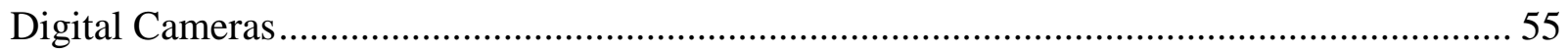

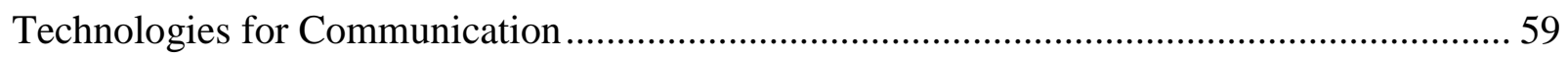

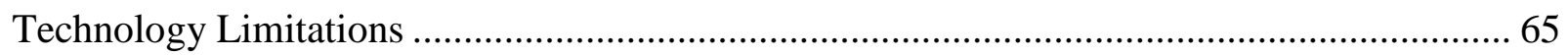

Chapter 6: Technology Supporting Children's Connection with Nature.......................... 71

Children's Connections with Nature through Technology …......................................... 71

Connection with Nature through Action-Oriented Suggestions ........................................ 75

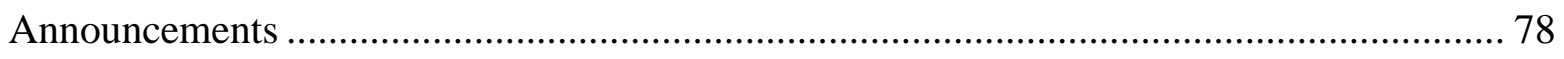

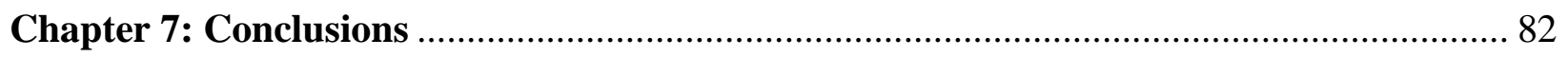

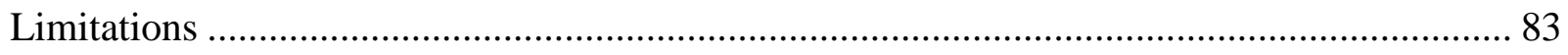

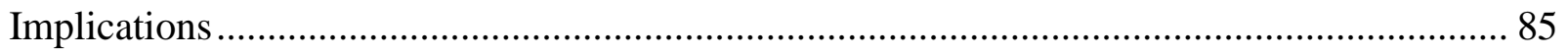

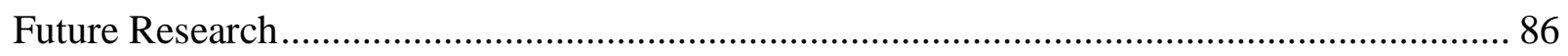

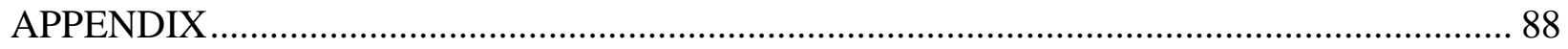

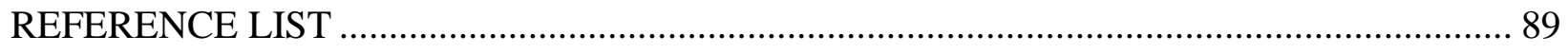




\section{LIST OF FIGURES}

Figure 1 - Group $3 a$ Environments - Brainstorming Chart..............................51

Figure 2 - Group $3 b$ Environments - Screenshot of Google Map............................53

Figure 3 - Group 3 a Environments - Findings Chart...................................54

Figure 4 - Brainstorming Chart for Grade One Group: What Do People Eat from the Garden?

Figure 5 - Brainstorming Chart for Grade Two Group: Environments (Dissemination

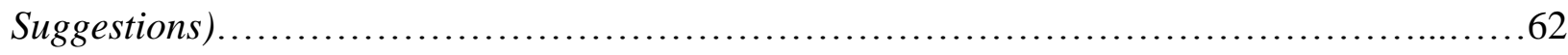

Figure 6 - Brainstorming Chart for Grade Two Group: Environments.......................63

Figure 7 - Draft of Letter to City Councillor from Grade Two Group: Environments.............64

Figure 8 - Draft of Letter to the Premier from Grade Two Group: Environments ..............65 


\section{LIST OF APPENDICES}

Appendix A - Ryerson University Research Ethics Board Approval ..........................88 


\section{Chapter 1: Introduction}

As an Early Childhood Educator, I have witnessed many children engage with and in nature. While the children I worked with had varied experiences such as planting seeds in a Styrofoam cup, examining frogs, or watching skunks as we went on a nature hike, many children acknowledged they enjoyed these experiences. This enjoyment can be seen in the experiences of many young children (Dawson \& Beattie, 2018; Elliot et al., 2014; Green, 2013). While I do enjoy and appreciate nature, I must profess that my experiences with and in nature are quite limited. Lately, and in the recent months of pandemic-related self-isolation and physical distancing, I find myself caring for the garden in my home where I grow flowers, herbs, and vegetables with my family. Outside of this, I do not feel particularly drawn to nature, at least not intrinsically. However, ever since I was young, and even to this day, I do find myself drawn to the use of digital technologies.

In addition to my own lived experiences with technologies as a child, it has been well documented that many children are engaging with digital technologies (Mantilla \& Edwards, 2019; Plowman et al., 2012; Slutsky \& DeShetler, 2017; Tena et al., 2019; Wu et al., 2014). Children's regular use of devices such as computers, iPads, and touch-screen phones can be seen as normative for many. This contemporary reality resonates with me as I am an advocate for the use of digital technology, whether for entertainment or for learning purposes. However, even though my experience with digital technology vastly outnumbers my experiences with and in nature, I do contend that experiencing nature is important, especially for children. This brings to light the area of interest and the focus of this research, namely, how children use digital technologies to explore nearby nature. 
This research paper is a secondary data analysis of an ongoing research study that explores children's engagement in ecological curriculum and research. I examine the experiences of children in grades one, two, and three, with a specific focus on children's use of technology in their ecological and nature-based research. This topic of study was chosen as limited research has been conducted that includes the experiences of very young children's ideas about and practical inclusions of technology with and in nature explorations. It is my aim to provide new insights for educators and researchers on how children utilize technology to engage with and in nature.

While this research is focused on a nature-technology discourse, there are a number of concepts that should be examined before pressing forward. These ideas interact to form the conceptual underpinning that informs this research and include: nature, place-based education, digital technology, and the sociology of childhood.

\section{Nature}

Nature can be understood as socially, culturally, and historically constructed (Foster, 2016; Ghafouri, 2014). As these aspects are contextual and differ across communities, nature is recognized as a complex and multilayered concept that has multiple definitions (Ghafouri, 2014). Foster (2014) proposed that nature has interrelated definitions which include: "1) the intrinsic properties or essence of things or processes; 2) an inherent force that directs or determines the world; and 3) the material world or universe..." (p. 19). The third definition articulated by Foster aligns with the notion of nature taken up in this paper.

Complementing this, Ghafouri (2014) stated that nature can be seen as having many forms and existing on a continuum from untouched wilderness to human-constructed 
environments. It is important to recognize that all different forms of nature have value and should not be thought of as existing on a hierarchy of importance. For example, a pot of flowers holds no less value than a tree in a forest. This acknowledgement is especially important for children and in work with children as they hold unique lived experiences in a range of contexts. As children experience aspects of nature within their local environment, they can also begin to appreciate nature and form positive connections with the natural world (Dawson \& Beattie, 2018; Elliot et al., 2014; Ghafouri, 2014; Green, 2013; Kahn \& Weiss, 2017).

Connecting with nature can be understood in a variety of ways. For example, an index developed for identifying children's connection to nature includes four dimensions: 1) enjoyment of nature; 2) empathy for creatures; 3) sense of oneness; and 4) sense of responsibility (Cheng \& Monroe, 2012). However, this understanding appears to be overlooking other factors at play. Broadening what it means for children to connect with nature is informed by Lumber et al. (2017) who argue that "nature connectedness is subject to personal and social influences and is comprised of cognitive, affective, learnt, experiential and personality factors that together, create a connection with nature" (pg. 3). This understanding is more inclusive of contributing factors and indicates that in making connections to nature, children can learn about, experience, and express an emotional disposition towards nature. When children connect to nature, it has also been put forth that they become ecologically literate as they are developing their environmentrelated knowledge, caring, and practical competence (Hammarsten et al., 2019).

\section{Place-based Education}

Place-based education is an educational philosophy and pedagogy that focuses on children engaging with local places and spaces to gain deeper understandings of and foster 
meaningful connections to their community and earthly environment (Somerville \& Green, 2011). Place-based education emphasizes hands-on learning experiences and aims to improve local community vitality and quality of the natural environment (Hougham et al., 2015). Furthermore, it acknowledges that place is not simply a geographic location, but it is also entrenched within inseparable historical, political, and ethical contexts (Iorio et al., 2017). These understandings take up a strong ecological focus as children engage with their local natural environments and also embrace the complexity of place; they are unique and subject to an entanglement of different contextual factors.

Approaches to place-based education differ as educators account for local contextual factors. Different environments hold deep histories, are situated in space, and are rich in potential as being a context for learning about the world. It is also important to acknowledge that one's notion of place can change depending on how they learn from and within it, what lenses they view places through, and how places change over time. While not an inherent barrier to engagement, the rise of technology over the years has changed how places can be explored, interacted with, and connected to.

\section{Digital Technology}

In this study, digital technologies are recognized to encompass different forms of electronic devices and applications. Aligned with Plowman et al. (2012), these include: 1) digital devices such as computers and touch-screen phones; and 2) products or outputs such as DVDs, websites, video games, and interactive stories that are viewed, read, played or created on these devices. Recent literature has highlighted that modern digital technologies are available, accessible, and utilized by children in their home and educational environments (Crawford et al., 
2017; Greenwood \& Hougham, 2015; Hatzigianni, 2018; Willis et al., 2014). Some modern digital technologies that are utilized by children include digital cameras, touch-screen tablets, smartphones, and computers (Boyce et al., 2014; Gomes et al., 2016; Holloway \& Mahan, 2012; Yelland \& Gilbert, 2018). These do not constitute a holistic list, but represent common technologies available to and utilized by children.

Furthermore, it is important to note that digital technologies are socially, culturally, and pedagogically relevant to young children (Johnston et al., 2018). As many children have access to and utilize technologies such as those listed above, these technologies can be seen as significant cultural tools that support children's developing understandings of their world (Johnston et al., 2018). Thus, digital technologies have the capacity to be used socially to support children's learning experiences.

\section{Sociology of Childhood}

The sociology of childhood developed and gained momentum as the children's rights movement was similarly growing. Together, they informed the United Nations Convention on the Rights of the Child in 1999 (Albanese, 2009). This school of thought rejects the notion of children being passive objects. Instead, children are viewed as agentic beings who actively participate and contribute to their world (Albanese, 2009; Quennerstedt \& Quennerstedt, 2014). Thus, children are not seen as being in the process of becoming an adult; but are valued as they are. Thus, as this research focused on children, it was imperative that their experiences and voices were central to this research. Children are viewed as capable and competent and in this study they can provide unique insights on their own technology usage. 


\section{Researcher Reflexivity}

My career as an Early Childhood Educator encompasses several years of practical experience and I have worked with children ranging from infants to school-aged children in licensed childcare settings. This professional experience guides this research study as I have an informed understanding of early childhood contexts. In many ways, my work can be considered research with children. My pedagogical approach necessitates observing and listening to children to make sense of their experiences, and in turn plan meaningful and enriching activities of interest to children. For example, I recorded instances of children's engagements as anecdotal notes and planned my activities accordingly. My years of practice and experience with children inform how I examine transcriptions of children's experiences and how I interpret data.

I also have knowledge of research designs and various methodologies which was attained from a master's level research methods course at Ryerson University. This course provided me with knowledge of various approaches to research and the opportunity to design a small scale research project, and enhanced how I critically reviewed research-based literature. In this and other graduate level courses, I conducted research on many topics within the scope of Early Childhood Studies. Altogether, these experiences gave me the opportunity to review relevant areas of literature on a selected research topic, relay findings of recent research, and identify gaps in literature that can be filled through new research. 


\section{Chapter 2: Literature Review}

This literature review encompasses the interacting aspects of children's experiences with nature, digital technology, and ecological research. As such, this review is organized into six sections: 1) children's experience of nature; 2) children as ecological researchers; 3) children's digital technology use; (4) children's digital technology use in early years and school environments; (5) children's use of digital technology to explore and connect to nature; and (6) children's utilization of digital technology to conduct ecological research. This review will provide necessary background information on my area of research, situate my work in the field, and present the documented lived experiences of children.

\section{Children's Experience of Nature}

\section{Importance}

The importance and benefits of children experiencing nature has been highlighted extensively in recent literature (see, for example, Coe, 2016; Collado et al., 2016; Dawson \& Beattie, 2018; Elliot et al., 2014; Ghafouri, 2014; Green, 2013; Kahn \& Weiss, 2017; Keniger et al., 2013; Rios \& Menezes, 2017; Tillmann et al., 2018; Williams \& Anderson, 2015). However, this embrace of the importance of experience in nature is not new. For example, in 1960, Harold Searles acknowledged that the non-human environment was important for human personality development (Kellert, 2009). Furthermore, and extending from Kellert \& Wilson (1993), Kellert (2005), and Louv (2008), Kellert (2009) further asserted that there was evidence that supported children's inborn need to interact with nature, and that their relationship with the natural world impacted children's health, productivity, physical, and mental well-being. This positive impact of time in nature on children's overall health, wellbeing, and holistic development is also 
identified in more recent literature as well (see, for example, Coe, 2016; Keniger et al., 2013; MacQuarrie et al., 2015). Furthermore, children's sensory engagement with and in nature is of great importance. As children interact with nature directly through touch, sight, sound, smell, and taste, they can begin to develop ecological ideas and environmental understandings through their embodied experiences (Beery \& Jørgensen, 2018).

Another important trend identified across recent literature is that through their experiences with and in nature, children can establish and strengthen a connection with nature (Coe, 2016; Collado et al., 2016; Elliot et al., 2014; Ghafouri, 2014; Green, 2013; Kahn \& Weiss, 2017; Williams \& Anderson, 2015). Children's connection with nature can be realized in a variety of ways. For example, children might show empathy towards plants and animals, be mindful and appreciative of beauty and diversity in nature and take on a stewardship role as they actively care for the more than human world. Furthermore, children's connections with nature during childhood may lead to a sustained environmental consciousness and positive environmental action that will extend into their adult life (Coe, 2016; Green, 2013; Keniger et al., 2013). Interestingly, though it has been argued that children who grow up in nature-deficient areas (i.e., urban communities) may be less likely to develop an appreciation for nature, it is important to acknowledge that nature exists in many forms (ex. indoor foliage, local animals) (Keniger et al., 2013). Thus, children can still experience nature in these environments. While these benefits may be evident, it is important to consider that there are multiple factors that can affect how children are impacted by their nature engagements (Tillmann et al., 2018).

\section{Connection}

Studies of children's experiences with and in nature and their connections to the natural world was quite prevalent in recent research (Collado et al., 2016; Dawson \& Beattie, 2018; 
Elliot et al., 2014; Ghafouri, 2014; Green, 2013; Rios \& Menezes, 2017; Williams \& Anderson, 2015). With respect to studies that focused on preschool-aged children, Green (2013) studied the autonomy of children aged 3-5 years in local places that were special to them. One of the study's findings was that children frequently visited and were connected to a range of nature forms such as a hillside and an undeveloped field. Furthermore, these children had knowledge of and an appreciation for the flora and fauna within these natural environments (Green, 2013). Another study that focused on the importance of nature for children in the context of a forest nature preschool found children engaging with nature in similar ways (Kahn \& Weiss, 2017). Children journeyed through different natural areas and interacted with soil, trees, and birds, all of which indicated these children were connecting with nature. Finally, Dawson and Beattie (2018) highlighted children's experiences during a nature walk within the context of an outdoor preschool. As they were walking, one of the children spontaneously spotted a group of eagles and communicated with the birds by speaking and singing (Dawson \& Beattie, 2018). These studies show that children's experiences and exploration of nature fosters the development of their relationship with the natural world.

The experiences of kindergarten children engaged with and connected to nature are also similarly evident in the literature. Elliot et al. (2014) followed kindergarten children's developing ecological awareness fostered through their weekly visits to a local forest. Children engaged in hands-on exploration in this natural environment; they found worms and cared for them and spoke about the forest in a manner which alluded to an affectionate connection (Elliot et al., 2014). A similar study closely observed the experiences of a kindergarten class during two spontaneous encounters with nature: finding a dead squirrel in their local park and a visit to a local farm (Ghafouri, 2014). Though their experience was guided by the pre-planned tour led by 
the farmers, the children observed and interacted with many different farm animals. Conversely, children's engagement with the squirrel was more spontaneous. These children understood that the squirrel was in need of care, and they brainstormed how they could help the squirrel find its family and keep 'him' warm and safe. While these two experiences of nature were very different, the researcher suggests that both of these encounters supported children's love for and appreciation of nature (Ghafouri, 2014).

The experiences and connections of older school-aged children to nature were also prevalent in this area of research. For instance, research on the experiences of grade six students engaged with their school learning gardens acknowledged that through acquiring cooking and gardening skills, and gaining science knowledge, these students were discovering ecological connections with different flora and fauna they interacted with in the garden (Williams \& Anderson, 2015). In a study of 5-10 year old children's understandings of nature, Rios and Menezes (2017) highlighted children's diverse experiences with and in nature. Children shared experiences with and knowledge of a variety of plants, animals, and sea creatures. Additionally, children identified problems which negatively impacted nature and suggested potential solutions to these problems. For example, children identified that sea animals get sick due to the amount of litter and garbage in the ocean. In an effort to combat this pollution, children suggested that barracks be placed into the sea in order to clean it (Rios \& Menezes, 2017). Similar findings of children's diverse experiences and knowledge of nature are identified in Collado et al.'s (2016) study of children's conceptualizations of nature. In addition to highlighting their knowledge of nature, these 6-12 year old children also articulated their views on different aspects of nature. For example, children described their positive emotional experiences when engaged in nature (e.g., tranquility, relaxed) and its aesthetic value (e.g., beautiful, incredible). Furthermore, children 
also acknowledged the impact that humans have on the environment and their related feelings of sadness and concern. As in Rios and Menezes (2017), the children also proposed actions that they could take to support nature such as recycling and preserving natural areas (Collado et al., 2016).

Children can experience many forms of nature and connect with nature in a variety of ways throughout childhood. Children who do not have access to wild natural landscapes such as a forest can form meaningful connections with nature that are inherent in their own communities such as local parks. Furthermore, as noted before, there are a variety of factors that can affect how children are impacted by their engagements with nature (Tillmann et al., 2018). It is important to acknowledge that one of these factors, with respect to children's educational environment, is the educator. It is critical for educators to enact a pedagogy that embraces the understanding that the natural environment is a teacher, and that they should be ready to engage with the spontaneous nature of natural environments (Dawson \& Beattie, 2018; MacQuarrie et al., 2015; Nazir \& Pedretti, 2016). If the educator understands this, they can be more supportive of children's planned and spontaneous engagements with nature and allow for increased opportunities for children to experience and learn from nature.

That being said, as educators facilitate experiences to connect children with nature, it is just as important to consider children's experiences with nature and their perceived connections to nature (Green, 2013). Educators should not assume, for instance, that children have access to natural spaces, what the quality of those spaces is, where interactions with the natural world occur, and how those engagements occur. Children have diverse knowledge gained through their unique lived experiences which when accounted for, can support educators in co-constructing experiences with and in nature. One way that these co-constructed experiences can be realized is 
in the active participation of children as researchers in ecological explorations. As will be detailed in the next section, children can be offered even more opportunities to engage and connect with nature when conducting ecological research.

\section{Children as Ecological Researchers}

Children are capable of being active and engaged researchers and can conduct meaningful research on aspects of their local environment. This capacity is realized in Listening to Children: Environmental Perspectives and the School Curriculum (L2C), a United Kingdombased project which aimed to gain insights of children to influence their school curriculum (Barratt Hacking \& Barratt, 2009). In this project, children aged 10-12 years old shared their experiences of their local community and environment, in order to make the school curriculum more relevant to them. Children expressed the importance of the local natural environment to them. They wanted to see more wildlife in their environment, keep the environment clean and safe, and take part in caring for the environment (Barratt Hacking \& Barratt, 2009). The promotion of children taking the role of researchers was integral in the project as they were recognized as environmental stakeholders, those who are or might be affected by decision making relating to the environment, and importantly, children were recognized as both present and future stakeholders (Barratt Hacking et al., 2007). As children engaged in the research, they were able to inform changes to their school curriculum which simultaneously affected how children were able to support nature.

Children have also taken the role of researchers in educational environments that adopted a place-based pedagogy (Jagger, 2013; Nxumalo, 2018; Somerville \& Green, 2011). For example, Canadian grade four children have been engaged in the process of community 
mapping, where they collaborated with other members of their community (ex. museum director and a First Nations liaison) to share local stories, experiences, histories, and images (Jagger, 2013). Somerville and Green (2011) shared the experiences of children aged 7-12 years old who engaged in nature learning through hands-on experiences and real-life investigations in their school. Specifically, children took leadership and participatory roles in a diverse range of environmental projects such as the restoration of coastal wetlands, marine research, cultivating food gardens, water and waste management practices, and the rehabilitation of coastal habitats (Somerville \& Green, 2011). Interestingly, preschool children have also been engaged in ecological research. Nxumalo (2018) highlighted children's interest in local bees and their efforts to co-conduct research on these bees with their educators and took positive and caring environmental actions including building the homes for bees and helping bees to locate flowers (Nxumalo, 2018).

The research highlighted here are but a few examples of children engaged as ecological researchers. What is important across these studies is that children engage in research in different ways and for different purposes. Children were engaged in ecological research in their school environment and in their broader community, and were interested in different members of those environments such as coastal habitats or local bees. Furthermore, a commonality of the research examined here is that regardless of what or how children were studying, they were seemingly connecting to nature through their explorations of and engagements with it (Jagger, 2013; Nxumalo, 2018; Somerville \& Green, 2011). Across all of these studies, as children conducted their research, they were immersed in the environment they sought to learn about. It is important for children to be recognized as competent and capable ecological researchers and the children featured in these studies exemplify the unique and meaningful contributions that children make 
to research widely and specifically to community and nature-based explorations. Recognizing children as such importantly and necessarily opens to them the opportunity to engage in ecological research, contribute their unique insights, and potentially strengthen their relationship with nature.

Just as children have experiences with nature, in this contemporary context, children also have experiences with digital technologies. Interestingly, children's experiences with digital technology are just as diverse as their experiences with and in nature.

\section{Children's Digital Technology Use}

Research has documented that many young children have experiences with digital technologies. Common technologies that children engage with and have been identified in recent literature include: television, computers, digital cameras, digital phones, touchscreen tablets, and video game consoles (Mantilla \& Edwards, 2019; Plowman et al., 2012; Slutsky \& DeShetler, 2017; Tena et al., 2019; Wu et al., 2014). These technologies are representative of what children have access to or experience with in their home environments. However, it is important to acknowledge that not all children have access to these technologies.

Unsurprisingly, given the proliferation of technology, these technologies are typically utilized by children on a regular basis, usually daily or several times per day. With respect to computer technologies such as touchscreen tablets or touch-screen phones, children have been observed to use them for between one and two hours a day (see, for example, Hosokawa \& Katsura, 2018; Oliemat et al., 2018; Przybylski \& Weinstein, 2019; Slutsky \& DeShetler, 2017; Tena et al., 2019) and for more than two hours a day (see, for example, Garriguet et al., 2016; 
Goode et al., 2019; Hinkley et al., 2018; Venetsanou et al., 2019). Similar findings are also noted for children's time spent watching television each day (Berglind \& Tynelius, 2018; Goode et al., 2019; Hinkley et al., 2018; Slutsky \& DeShetler, 2017). With respect to computer technologies, these forms of technology use can be understood as a relatively new form of play for children (Oliemat et al., 2018; Slutsky et al., 2019) and has evidently become a part of children's daily lives.

It is important to acknowledge that these technologies can be utilized in a variety of ways. The multimodal features of computer technologies are of particular interest as data ascertained directly from children indicated many children utilize screen-based technologies for a variety of purposes such as taking pictures, playing games, watching videos, or engaging in educational applications (Mertala, 2016; Oliemat et al., 2018). This is an interesting insight as the manner in which children utilize computer technologies is subject to debate. That is, the use of these computer technologies could be classified as playing or learning or as educational vs. non-educational uses (Hosokawa \& Katsura, 2018; Oliemat et al., 2018; Plowman et al., 2012). While this research has made distinctions between playing and learning and educational vs. noneducational, other research has indicated that children learn through play (Bergen, 1988;

Bubikova-Moan et al., 2019; Golinkoff et al., 2006; Pyle \& Alaca, 2018; Pyle \& Bigelow, 2015). This is also true for digital technologies as children can learn through playing video games on computers-based technologies (Hung et al., 2015; Miller, 2018). Thus, though activities such as video games can be perceived as non-educational, children are in actuality learning through these experiences. As uses of technologies cannot easily be classified into strict binary groupings, it is more important to acknowledge that technologies have been, and continue to be, utilized in a multitude of unique and engaging ways. 
With respect to children's home environments, if, how, and to what extent children engage with technology is influenced by their family members (see, for example, Hinkley et al., 2018; Hosokawa \& Katsura, 2018; Plowman et al., 2012; Slutsky \& DeShetler, 2017; Tena et al., 2019; Venetsanou et al., 2019; Wu et al., 2014) as well as their own individual interest (Slutsky et al., 2019; Tena et al., 2019). Caregivers and siblings can act as role-models for their children and can guide the content of children's screen-time activities. However, children are also agentic beings and make decisions for themselves. Thus, not all children choose to include technology in their play activities and may prefer other forms of play at home.

\section{Children's Digital Technology Use in Early Years and School Environments}

Given the proliferation of and children's general interest in technologies, educators often look to bring technologies into their curriculum and pedagogy and children now regularly use digital technologies in formal learning contexts. The technology available to children in their early years and school settings typically mirrors the technologies that are available to them in their home environment. These technologies include digital cameras, video cameras, desktop computers, and touch-screen tablets (see, for example, Dockett \& Perry, 2005; McKenney \& Voogt, 2010; Otterborn et al., 2018; Plowman et al., 2010; Yelland \& Gilbert, 2018). While this literature identifies this to be the case with many learning environments, there are educators who choose not to utilize these technologies in their classrooms. An example of this situation is detailed by Oliemat et al. (2018) in their study of children's experience of their kindergarten classroom. However, and interestingly, within this research, it was also asserted that the kindergarten curriculum should incorporate the use of touch-screen tablets and implement 
appropriate strategies and guidelines to support children's tablet use in schools (Oliemat et al., 2018).

The primary reason for including digital technologies in early learning environments and schools is that digital technologies can be beneficial to children's learning and provide children with experiential advantages (Hatzigianni, 2018; Mertala, 2019; Yelland \& Gilbert, 2018). For example, computer technologies can provide children with additional opportunities to engage in math, science, and various language and literacy skills (e.g., reading, writing, print knowledge, phonological awareness, and oral language) (McKenney \& Voogt, 2010; Otterborn et al., 2018; Reeves et al., 2016). However, some may wish for children to gain experience in using these technologies so they can learn about technology. This integration and utilization of digital technology in schools to improve and enhance children's learning experience is not a new phenomenon, as evidenced in earlier research that identified computers as being helpful to students' understanding of core concepts in science, math, and literacy (Roschelle et al., 2000).

Despite its educational and experiential potential, utilizing technology to improve children's education is not a simple and straightforward task (Hatzigianni, 2018; Johnston et al., 2018; Roschelle et al., 2000; Yelland \& Gilbert, 2018). The use of technology should be thoughtful and educators should carefully consider why these technologies are being used and how they are to be used. Given their multimodal nature, technologies such as the touch-screen tablet can be supportive and extend children's learning experiences in unique ways (Yelland \& Gilbert, 2018). However, if educators are to be truly open and inclusive in their curriculum planning, they must also incorporate children's insights and opinions as well. Many children have lived experiences with and hold much insight into digital technologies (McKenney \& Voogt, 2010; Oliemat et al., 2018; Reeves et al., 2016) and should be consulted with to 
determine how technologies can be used in their educational environments. These environments can extend beyond the classroom and include the use of technologies to explore the natural world.

\section{Children's Use of Digital Technology to Explore and Connect to Nature}

Literature highlights the many ways that children can use digital technologies to explore nature and the plethora of devices that can enable these engagements. The planned use of digital technology to support children in building connections to the natural world has been recommended for preschool and school-aged children (Holloway \& Mahan, 2012; Willis et al., 2014). It is important to note that children connecting with nature through technology was theorized in this research as these suggestions were not implemented in practice. For example, Willis et al. (2014) detail the different types of technologies (e.g., digital cameras, mobile computers, probeware) that educators could provide to preschool-aged children in their open explorations of nature. Similarly, Holloway and Mahan (2012) shared a digital storytelling experience for school-aged children to be directed and assessed by the educator. Though it was noted in each of these examples that children could connect with nature through their respective experiences with technology, it was interesting to see the apparent priorities of these different approaches. With respect to the school-aged children example, the predetermined activity is reflective of a school environment that may often focus exclusively on prescribed learning outcomes. When compared to the research on the open nature explorations of preschool children, school-aged children connecting with nature appeared to be more of a positive side-effect of this learning experience instead of a central curricular intention. 
While these suggestions were not implemented in practice, literature that has examined children's realized use of digital technology with and in nature suggests that children are indeed making connections with nature through their use of digital technologies. This was quite prevalent in a research study which aimed to utilize touch-screen tablets to invite school-aged children to engage with nature on a nature hike (Boyce et al., 2014). Children used this technology as a supplementary reference tool for data collection, and to engage directly with and in nature through photography, a hike related application, and audio and video recordings. These children articulated that they were very interested in returning to the hiking site and were noted to be interacting with nature positively, for example, by interacting with different insects and listening for bird calls (Boyce et al., 2014).

Similar findings were shared by researchers focusing on older-school aged children who utilized a touch-screen tablet software application to engage with nature in various park-based environments (a wetland, prairie grassland, and an indoor tropical garden) (Crawford et al., 2017). Children were noted to be connecting with nature, and additionally, many children also articulated that their experience with technology in nature was fun. Like Crawford et al. (2017), McClain and Zimmerman (2016) studied children's technology use with and in nature but within the context of a summer camp. These children went on a nature hike and were provided a touchscreen tablet equipped with an e-trailguide software application. This application provided children with information on different aspects of nature they observed, such as grapevines and trees, and allowed children to enter data and draw pictures of things that interested them. While this research concluded that the use of technology could benefit children's learning experience in nature, it was also noted that many of the children were emotionally and personally connected to 
nature (for example, as children learned that wild grapes are native to their local context) during this experience (McClain \& Zimmerman, 2016).

As detailed above, it is evident that digital technologies hold the potential for supporting children's connections with nature. While some research only theorized that technology could be beneficial in this matter (Holloway \& Mahan, 2012; Willis et al., 2014), research that examined children's actual realized use of digital technologies in nature further solidifies this assertion. Interestingly, this use of technology could also be seen as a barrier to children's sensory experiences with and in nature. Given this, it has been suggested that children should think of technologies used within nature as tools that extend, but not replace their senses (Hougham et al., 2015). It is also important to acknowledge that this research incorporated the views and experiences of children and did not solely rely on the researchers' or educators' perspectives and opinions.

\section{Children's Utilization of Digital Technology to Conduct Ecological Research}

Just as digital technologies can support children's relationship and connection with nature, they can also be utilized to conduct ecological research. The literature highlights how many children have utilized digital technologies to conduct ecological research (see, for example, Blatt, 2013; Gomes et al., 2016; Green, 2016; Hougham et al., 2018; Kacoroski et al., 2016; Land \& Zimmerman, 2015; Song et al., 2012). Some of the technologies used by children in their research include wearable digital cameras, touch-screen tablets, computers, smartphones, a digital microscope, global positioning system (GPS) technology, and audio recorders. These technologies were utilized for different aspects of their research and to support both their primary and secondary data collection. For example, in one study, children utilized wearable cameras to 
record their experiences on a nature walk (Green, 2016). As children were free to record their own experiences, they could decide what they wanted to explore and record their own unique insights. In other studies, computer technologies such as smartphones or touch-screen tablets were utilized as a data source for written and visual information on local nature such as butterflies, macro-invertebrates, or their school vineyard (Gomes et al., 2016; Kacoroski et al., 2016; Song et al., 2012). In these examples, children were also free to pursue their own research focus (e.g., chrysalis and transformation, what plants butterflies prefer, identification of macroinvertebrates).

Research with middle school-aged children seems to be less open-ended and more structured as seen through several studies that detailed children's research on trees. Excerpts from these various research ventures included children utilizing microscopes and touch-screen tablets to observe and identify different leaves from trees (Hougham et al., 2018), gathering scientific insight from an iPad software application that supports tree investigations, (Land \& Zimmerman, 2015), and utilizing a variety of technologies (e.g., GPS technology, computers, Microsoft Excel) to collect data and disseminate findings for a variety of research questions (e.g., percentage of each type of tree in the field research site, location of each of the trees in the field research site) (Blatt, 2013).

Taken together, the majority of this research appears to be focused on children's learning outcomes, and in particular science learning expectations (Blatt, 2013; Gomes et al., 2016; Hougham et al., 2018; Kacoroski et al., 2016; Land \& Zimmerman, 2015; Song et al., 2012). While it is acknowledged that children's research inquiries can stem from their interests, and children can connect with nature through technology, the overarching motivation for the use of these technologies appears to be enhancing children's learning experience of predetermined 
disciplinary learning expectations (e.g., science, technology, math) (Anderson et al., 2015; Hougham et al., 2015).

\section{Significant Themes}

While this literature review is not exhaustive, there are some prevalent themes across studies. First, there is very little research that addresses how digital technology can (or cannot) affect how children connect with nature (Boyce et al., 2014; Crawford et al., 2017; Hougham et al., 2015; McClain \& Zimmerman, 2016). Second, there is limited research that includes the voices and insights of children (Boyce et al., 2014; Crawford et al., 2017) and no research on the inclusion of very young children's ideas and insights into using technology with and in nature. While Oliemat et al. (2018) does actually include kindergarten-aged children, the research focus is not utilizing technology with and in nature. As a result, this reveals the third theme which is that almost all of the findings present in literature focused on children's use of digital technology with and in nature were derived from an adult perspective.

As recommended by Kacoroski et al. (2016), future research must examine closely the relationship between digital technologies and nature to determine whether technologies can enhance children's connection to nature. While this gap in research is present, this research also necessitates that the voices and experiences of young children must be accounted for. Future research should not be left solely to the adult perspectives, especially if this research centres on children. This research study addressed this identified gap as it explored how digital technology can be utilized by children to engage with and in nature and included the perspectives of children. 


\section{Chapter 3: Research Design}

This study was a secondary data analysis of an ongoing research study that explored children's engagement in ecological curriculum and research. In this section of the MRP, I provide an overview of the primary study's design to detail its theoretical underpinnings, context, and procedure. Afterwards, the research design of this secondary data analysis is detailed.

\section{Primary Research Project: Empowering Young Citizens}

Empowering Young Citizens is an ongoing study conducted by Dr. Susan Jagger that focuses on children's participation in ecological curriculum and research related to their school garden and nearby nature. Specifically, Dr. Jagger's study aims to accomplish three goals: 1) explore how children's participation in curriculum and research can evolve through participatory research in a school-based garden; 2) examine if and how children's participation in school garden-based curriculum and research influences their developing ecological citizenship; and 3) identify potential facilitators and barriers to children's participation in school garden-based curriculum and research. ${ }^{1}$

\section{Primary Research Project: Theoretical Framework}

Empowering Young Citizens is informed by three assemblages: the sociology of childhood, children's rights, and place-based education. Firstly, the sociology of childhood purports that childhood is a socially and culturally constructed concept, and that perceptions of the child as innocent or child as becoming limits, and even inhibits, children's participation in

\footnotetext{
${ }^{1}$ The data analyzed is from the Empowering Young Citizens project funded by a SSHRC Insight Grant.
} 
matters that involve them (Kellett et al., 2004). Given this understanding, the sociology of childhood conceptualizes children as active, creative, and social change agents who are experts in their own lives and whose voices and views should be taken seriously (Corsaro, 2005; Langhout \& Thomas, 2010; Mayall, 2002). With respect to children's rights, the United Nations Convention on the Rights of the Child (UNCRC) calls for the inclusion of children's voices and participation in matters and actions that concern them (United Nations Convention on the Rights of the Child, 1989; United Nations, 2005). Importantly, children have the right to express their views and opinions, have those contributions given due weight, and participate in decisionmaking related to the community and environment that they live with and in (Lundy et al., 2011; Pascal \& Bertram, 2009). Lastly, place-based education situates the learner and learning in the local environment. It emphasizes the value of hands-on and real-world learning experiences and the positive impact that such experiences can have on the learner's developing connections to community, appreciation of the natural world, and commitment to active and informed citizenship (Sobel, 2004). Taken together, these theories highlight the importance of children being actively involved in their environmental learning experiences and listening to their unique and valuable insights in the context of their educational environments.

In reflecting on these complementary frameworks, I happily contend that my thinking and practice aligns with the theories that guide Empowering Young Citizens. In my professional experience as an early childhood educator, I always aim to ensure that all children I work and learn with are treated and respected as capable agentic beings, regardless of their age. I am a firm believer that all children have unique lived experiences and have diverse capabilities. As such, each child brings something new to this world and their very being should be valued. I also believe in the rights of children. I contend that children's rights should be respected, and that 
these rights should be realized through actions, not just words. Finally, I believe place-based education to be a meaningful and enriching opportunity for children to experience and engage with their local environment. I also believe that these experiences can be more rewarding for children than standardized or generic curriculum and pedagogy as the learner is situated in their local context and takes on a more active and empowered role in their educational journey.

\section{Primary Research Project: Setting and Participants}

Empowering Young Citizens takes place in a public inner-city elementary school (Kindergarten - grade six) located within Toronto, Ontario. This school will be referred to as School $\mathrm{Z}^{2}$. School $\mathrm{Z}$ is diverse with more than 650 children attending and about $85 \%$ of these children speak English as a second language with about 50 language groups represented. School $\mathrm{Z}$ is also part of the Model Schools for Inner Cities initiative which intends to ensure that all children and families have access to the same opportunities and social supports regardless of challenges they may face (e.g., language barriers, poverty). Furthermore, School Z has an established school garden that is accessible to the children and whose programming is facilitated by a local, not for profit community-based gardening group.

Dr. Jagger has an existing relationship with School Z through earlier research with primary and junior classes that explored the school garden experience through participatory research with children in grade six. Drawing on these collaborations, Empowering Young Citizens is a longitudinal study that focuses on younger children in their first years of elementary school. The participants of Empowering Young Citizens include children from one grade one class (2017/2018), two grade two classes (2018/19), two grade three classes (2019/20), and two

\footnotetext{
${ }^{2}$ All identifying names of people, places, and events have been changed to pseudonyms to protect the confidentiality of participants and the research site.
} 
grade four classes (2020/21), teachers, and school administrators. It is important to note that the participants change over time as the grade and class assignment of children (and teachers) change each school year and students move to and away from the school community. While the sample is not consistent across all years, participation of children over time provided an increased opportunity for additional insights as data will be collected with and from a broad range of children. In addition, this research also includes children who participate over several years, for example, in grades one, two and three. Examining the experiences of these children longitudinally can reveal a more holistic understanding of children's evolving participation and developing ecological citizenship.

\section{Primary Research Project: Approach}

To explore the three main research questions, Empowering Young Citizens follows a participatory research approach. Participatory research involves its participants in the processes of planning, acting and observing, and reflecting and revising, and encompasses a collaborative process (Canosa et al., 2018; Horgan, 2017; Kemmis \& McTaggart, 2005). Additionally, participatory research is emancipatory: it aims to support and empower those who are constrained or limited by social structures (Kemmis \& McTaggart, 2005; Shamrova \& Cummings, 2017). Children's rights to participate are recognized as children are actively involved and empowered to make decisions and take action in this research (Canosa et al., 2018; Horgan, 2017; Lundy et al., 2011; Kirby, 2002; Raffety, 2015).

Interestingly, there are important intersections of participatory research and environmental education that should be noted. Both participatory research and environmental education are centred on motivating positive social and environmental change and providing 
opportunities for children's engagement in critical thinking, questioning, and researching (Mordock \& Krasny, 2001). As such, participatory research and environmental education can embrace contextual complexities, active involvement of stakeholders, and navigation through social, cultural, political, historical, and environmental currents (Robottom \& Sauvé, 2003). It follows that children cannot engage in environmental learning by standing on a sideline and letting someone else do the exploring for them. Instead, participation in content and contexts itself opens pathways for change in a more action-oriented approach to curriculum and research. Thus, participation is not just encouraged, it is necessary in environmental education.

\section{Primary Research Project - Research Process}

Over the course of each school year, Dr. Jagger and a research assistant spend at least one morning or afternoon per week with each of the participating classes. Two research assistants have been involved in the research, though Dr. Jagger only worked with one assistant at a time. Meghan, a recent graduate of an early childhood education undergraduate program, worked with the Grade One and Grade Two classes and Leah, a recent graduate of a Master of Early Childhood Studies program, worked with the Grade Three classes and will work with the Grade Four classes.

The data collection of Empowering Young Citizens is organized loosely into three phases. These phases are consistent across each school year and grade level with some exceptions ${ }^{3}$. In the first few weeks of the school year, the research team consisting of Dr. Jagger and a research assistant first introduce themselves to the children and spend time with classes, learning the culture and routines of the children, teachers, and the school. Consent forms are sent home to the families, and assent is obtained from the children. Assent from the children is not only important

\footnotetext{
${ }^{3}$ The grade three data collection came to an abrupt end in March 2020 due to COVID-19 related school closures.
} 
to confirm that the researchers are respecting the children's rights to choose to participate, but also to ensure they are informed of the nature of this research and their right to refuse to participate. Once consent and assent are received, the initial data collection process begins.

The initial data collection has the research team engaging with children through a variety of activities that focus on the children's ecological understandings and questions. These include inviting children to create drawings/maps of their community or neighbourhood, participate in whole class and small group sharing and discussion of drawings/maps, and small group and whole class brainstorming of what they know and wonder about their schools garden and nature in their community, as well as what they want to learn about. This brainstorming is compiled into Know, Wonder, and Learn (KWL) charts.

In the next phase of research, children begin their own research projects in small groups based on the shared questions from their KWL charts. In this collaborative initiative, children work together in small groups based on their interests and questions from the initial data collection. They are supported by the research team in planning, data collection, data analysis and dissemination. Children are free to collect data from various sources of their choosing, and are also provided with digital cameras that they could choose to use in their research. Once the data are collected and analysed by the children, their findings are shared in ways chosen by the children (e.g., a play, comic strip, posters).

During each research session, the research team collects field notes and photographs of the children's engagement in curriculum and research. Audio recordings of the research sessions and research talks with the children are also collected. Dr. Jagger provides each group of children with a folder to store their work. These include children's individual and group work 
samples from the sessions. At the end of the school year, and as in the initial data collection, children are invited to create and share drawings/maps of their community or neighbourhood, and KWL charts. This final data collection takes place in small groups and as whole class discussions.

\section{Research Design of the Secondary Data Analysis}

This secondary analysis of data from Empowering Young Citizens follows a qualitative research approach. First, with respect to defining qualitative research, it is important to note that there is no one universal way of conducting qualitative research. Instead, it can be described as an emergent, inductive, interpretive and naturalistic approach to examine the lived experiences of people (Yilmaz, 2013). This description is holistic in that it accepts that the processes of qualitative research are varied and also notes the importance of context.

The foundations of qualitative research come from research within a variety of areas including anthropology, sociology, and the humanities (Creswell \& Creswell, 2018). Qualitative research can be enacted in a variety of ways, for example, through narrative research, phenomenological research, and ethnography, and is guided by a constructivist paradigm which recognizes reality as dynamic and socially constructed (Creswell \& Creswell, 2018; Yilmaz, 2013). Within this paradigm, key areas of focus include the processes of individual interactions and accounting for the specific contexts in which these take place (Creswell \& Creswell, 2018). Thus, some of the characteristics of qualitative research include: collecting data in natural settings, ascertaining data from multiple sources, embracing researcher reflexivity, and analyzing data through induction and deduction (Creswell \& Creswell, 2018). Qualitative research focuses on rich details, complexities, interpretations of lived experiences, and situating these in context 
(Creswell \& Creswell, 2018; Gillies \& Edwards, 2005; Irwin et al., 2012; Leech \& Onwuegbuzie, 2007; Yilmaz, 2013). It is also imperative to acknowledge that qualitative research recognizes multiple truths, meanings, and realities (Creswell \& Creswell, 2018; Yilmaz, 2013). As such, a qualitative approach is beneficial in this study as the research intends to provide insight into the experiences of participants and contextually situate these understandings.

For the purpose and intentions of this study, a quantitative research approach would not be appropriate or meaningful. Quantitative research often focuses on acquiring outcomes, making generalisations and predictions, and identifying cause-effect relationships (Yilmaz, 2013) and in this study, would require the quantification of qualitative data. With this data set, contextual meanings and situated understandings would be lost in the quantification of experiences and would result in the production of generalized interpretations derived from numbers and statistical analysis. Qualitative data must be met with qualitative methods to retain its unique richness, complexity, and contextual situatedness (Leech \& Onwuegbuzie, 2007).

\section{Research Design-Secondary Data Analysis}

My research design includes a secondary data analysis of data from the Empowering Young Citizens research project. A secondary data analysis can be understood as the process of utilizing secondary data to produce new understandings in a particular area of interest (Irwin, 2013; Johnston, 2014). Secondary data refers to data that is made available for use by people other than the primary investigators (Pienta et al., 2011).

Secondary data analyses can have a range of goals. Hinds et al. (1997, as cited in Ruggiano and Perry, 2019) highlight four such purposes: 1) focusing on a different unit of

analysis utilized in the primary research; 2) providing an in-depth analysis of themes found in the 
primary research; 3) analyzing data that is not the primary focus in the primary research; and 4) comparing data in the primary research to newly collected data. Additionally, Heaton (2004, as cited in Chatfield, 2020) suggests that secondary data analyses can be utilized to explore new research questions, compare findings, or conduct a meta-study.

With respect to the purpose of this secondary analysis, I conducted an analysis of an aspect which emerged from the primary research data set but was not that study's primary area of focus; this approach can be understood as a supplementary analysis (Heaton, 2008). Whereas Empowering Young Citizens broadly explores children's participation in ecological curriculum and research and their developing ecological citizenship, the focus of this study was children's use of technology in their school garden and community nature-based research. Broadly, I considered how children used technology to explore nearby nature. Within this, I specifically examined the following research questions:

1) What technologies do children use?

2) How can technology help children to connect to nearby nature?

3) How can technology engage children in nature and ecological related research?

It is important to acknowledge that there are some potential challenges that are inherent in secondary data analyses. Some of these include: insufficient data to explore the research question(s) and no option to generate new data from the primary participants; the new researcher lacking knowledge of the primary context; and a potential for ethical issues regarding participant identities and confidentiality (Chatfield, 2020; Gillies \& Edwards, 2005; Hammersley, 2010; Irwin, 2013; Ruggiano \& Perry, 2019). While the problem of the data being insufficient may be inherent as the primary research was conducted for another purpose (Johnston, 2014), in 
consulting with Dr. Jagger, it became apparent that there is considerable data within the primary data set that is relative to this study's research questions. With respect to the new researcher`s understanding of the context in which this research takes place, I discussed the research project and context in detail with Dr. Jagger in many meetings and discussions to better understand the research space. My own professional experiences in early learning and school environments similarly helped me to familiarize myself with the research context. In terms of potential ethical issues, these are mitigated through only reviewing data where the participant`s identity has been already made anonymous by the research team.

While these potential challenges can seemingly restrict the ability of secondary data analyses to provide new information, especially when compared to a typical qualitative research study that collects primary data with and from participants, there are many positive aspects of this type of research as well. First, secondary data analyses open an opportunity for researchers to test new ideas, theories, frameworks, and models of research design (Johnston, 2014). As noted before, secondary data analyses can be designed in multiple ways and for a variety of purposes. In this study, the method is employed to interpret the experiences of the child participants related to digital technology. Secondary data analyses also provide an opportunity for a new researcher to answer new questions (James, 2013). As the primary researchers had their particular research questions in mind when conducting data collection, a secondary data analysis can re-interpret data or highlight data not utilized by the primary researchers.

In this study, new findings derived from the Empowering Young Citizens data set are trustworthy as they can be understood as occurring naturally. However, this study was subject to my bias. As noted before, I have a disposition towards digital technology and not so much for nature. This impacted how I framed this study's research questions as I only focused on aspects 
of the data related to digital technologies. This also affected how I analyzed data as I had preconceived notions of what digital technologies children have experiences with and how technologies could be used by children to connect with and in nature.

\section{Participants \& Setting}

The Empowering Young Citizens participant data analyzed in this secondary data analysis included data from children from a grade one class (2017/2018); two grade two classes (2018/19); two grade three classes (2019/20). The grade one participants include 19 children from a single class; the grade two participants includes 27 children from two classes (15 and 12 children respectively); and the grade three participants include 29 children from two classes (15 and 14 children respectively). The names of all participants, places, and events have been changed to protect and respect the confidentiality of participants. The only exceptions are the names of the members of the research team: Dr. Susan Jagger, Meghan, and Leah. Furthermore, it is essential to note that I only reviewed data where the participants' identities had already been anonymized by members of the research team.

After I received the approval to conduct this research from Ryerson University's Research Ethics Board (see Appendix A), I was given access to Dr. Jagger's anonymized data set. In terms of security, only Dr. Jagger, her research team, and I have access to this anonymized data which is only accessible through a Ryerson password protected Google Drive. All consent and assent documentation and pseudonym keys were removed from the shared data set; only Dr. Jagger and her research team have access to this information. 


\section{Data Analysis}

The data set analyzed in this study included all transcriptions of conversations and discussions during the children's research processes, photos of children's research plans, small group and whole class KWL chart pictures and discussions, and copies of children's artwork and notebook contributions. With respect to the children's research processes, these included research planning, data collection, reflecting on research results, dissemination, and discussions on future actions.

To begin my review of the data set, I utilized a constant comparison analysis. A constant comparison analysis is a technique derived from Glaser and Strauss' (1967) grounded theory. Grounded theory is a research design that encompasses analytic practices that reveal themes or theory grounded in a data set (Collingridge \& Gantt, 2008; Creswell \& Creswell, 2018; Tracy, 2010). This analytic method was chosen as it allowed me to go through the data multiple times and organize my findings into coherent categories. This recursive process would eventually illuminate themes in the primary data.

The constant comparison analysis began with my initial read through of the entire primary data set (Leech \& Onwuegbuzie, 2007). In doing so, I focused on children's discussions of technology in their research planning and research products. This was done chronologically by grade level and by each separate class. To complement this, as I collected and reviewed the data, I sorted and organized all relevant data into password protected word files and separated them by grade and classroom.

As I read through the data, the next phase of the constant comparison analysis began as I started to code the data. Coding is the process of organizing data to provide an overview of 
essential data in relation to the research question(s) (Elliott, 2018). Essential data were assigned codes, or labels that represent a symbolic meaning (Saldaña, 2009; Elliott, 2018; Leech \& Onwuegbuzie, 2007). For this research, I followed a three-stage coding process of open coding, axial coding, and selective coding (Neuman, 2004; Saldaña, 2009).

I conducted open coding during my initial read through of the data. First, I took a deductive approach to coding and included pre-identified codes that were formed before delving into the research (Leech \& Onwuegbuzie, 2007). These codes included the use of the term or engagement with computers, tablets, internets, and video games. These represented the digital technologies I assumed children may utilize in their research. My goal was to identify every instance that technology was included in the data set, whether it was children mentioning this technology in their conversations or actually utilizing it. However, as I did not know what I would find within the data, I also embraced an inductive approach and welcomed the possibility of new codes emerging from the data (Leech \& Onwuegbuzie, 2007). I worked between both deductive and inductive approaches to coding as I felt it was important to include technologies that were present in previous research, as well as be flexible and inclusive of findings outside the scope of these predetermined codes. Once I finished the open-coding stage, I began the axial coding stage.

The axial coding stage started as I engaged in another read through of the data and reviewed my initial codes. Following this review, I started to make connections between themes and combined some thematic categories into broader groupings (Neuman, 2004, Saldaña, 2009). These categories include: types of technology, use of technology, and children's perceptions of technology, and can be identified as initial themes of this data. After working between themes and data, and reviewing the initial codes, I moved on to the selective coding phase. 
The selective coding phase encompassed reviewing codes from the open and axial coding phase and placing them under overarching codes. These codes represent solidified themes that are grounded in the data set (Saldaña, 2009). Once the overarching themes were constructed, I reviewed the data again to find further evidence to confirm and strengthen my findings (Neuman, 2004). Once concluded, I reviewed my findings with Dr. Jagger to discuss how these themes represented the experiences of the primary participants and to ensure what was presented was an accurate reflection of what happened. I also thought these discussions would be insightful as technology was not the focus of Dr. Jagger's primary data. 


\section{Chapter 4: Children's Knowledge and Use of Technologies}

After reviewing the original data set, it was clear that many of the children in the Empowering Young Citizens project had knowledge of and experience with a variety of digital technologies. These technologies included televisions, computers, and touch-screen tablets, and were consistently identified across all three grades (grades one, two, and three). This is not surprising as many young children have experiences with these and additional digital technologies in both their home (Mantilla \& Edwards, 2019; Plowman et al., 2012; Slutsky \& DeShetler, 2017; Tena et al., 2019; Wu et al., 2014) and school environments (Dockett \& Perry, 2005; McKenney \& Voogt, 2010; Otterborn et al., 2018; Plowman et al., 2010; Yelland \& Gilbert, 2018). The presence of digital technologies in the data set indicates that these technologies are familiar to these children and that they have experience with them.

\section{Television}

While television was not utilized in the school, it is a technology that was identified to be a source of information for multiple children in their home environments. For example, Letch, a grade one participant, identified knowledge learned from television during a discussion about their end of the year nature drawings:

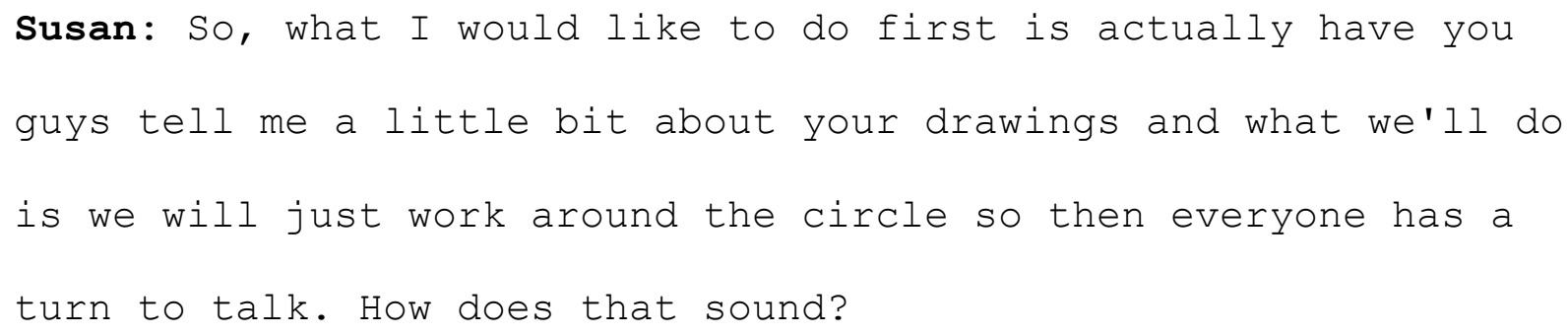


Susan: OK, let's keep going around in the circle. Letch do you have anything to add?

Letch: In my TV I heard of a flood and the roots grabbed all of the water from it.

Similarly, grade two participant Batman referenced their experience with television during the research planning stage of their study of birds' habitats and behaviour:

Susan: Oh. So how do you find out about that bird? Cause you know a lot about how that bird acted. How do you know?

Batman: Because I saw it on TV.

A third example is seen during a grade three group discussion about how their group could find out about where waste comes from and how they could keep their world healthy. Clara reflects on a past experience:

clara: When we were away from Canada and in Trinidad in the Caribbean Islands there used to have a TV and we used to watch videos on presentations by people who work at the garbage truck. Like how they are trying to help the world to recycle, put the compost stuff in the compost, put the garbage in the garbage and trying to reduce the amount of garbage and more recycling stuff. 
These examples of children's experiences with television suggest that participating children have lived experiences with television and can learn from this technology (Cain, 2017). While Letch and Batman reference their experience with television simply, Clara's reflection highlights that children can gain detailed understandings through different technological media and in this case, television. Clara understood and seemingly deduced that the actions of recycling and composting that she saw on TV reduces the amount of garbage produced and can be helpful to the world. As many children spend time engaging with television (see, for example, Berglind \& Tynelius, 2018; Goode et al., 2019; Hinkley et al., 2018; Slutsky \& DeShetler, 2017), it can be concluded that children gather a range of information from this technology and this could motivate additional use of this technology as a source of information.

\section{Computer Technologies}

In addition to knowledge of and experience with television, children have experiences with computer technologies. These include technologies such as a desktop computer, laptop, touch-screen phone, and touch-screen tablet. Moreover, multiple children across all three grades identified some knowledge of or experience with computer technologies. For example, a participant in grade one, Shark Boy, identified their use of this type of technology during the year end discussions about their nature drawings. While talking about their drawing of their school garden and nature in their community, Shark Boy referenced an experience with YouTube:

Shark Boy: ... and here's some grass and I drew trees and I started thinking, first I just drew all the different types of birds then I was like "what should I name them all" and I was like "oh 
I remember the time when I saw that nightingale" so I wrote nightingale here. Then that hawk I saw earlier in the school last year that's why I wrote hawk and then a blue jay I saw on YouTube and a robin I saw on a trip and a sparrow which I usually see around in my balcony, would sit on my bike a lot.

More examples are highlighted by grade two participants, Ronaldo and Drift. In the data collection phase of their research, Ronaldo detailed how they conducted research at home:

Ronaldo: I research at home because in my room I have my own tablet so I go on stuff like science, math, and research on stuff because sometimes I go and see and research if I find something really cool, I go in and grab a paper and take one of my pencils and then just write about it. But I think and if I don't get something I just sit in my computer, it's my dad's computer. Or my tablet. So then I would know more information about it. I do that so I know more so then I learn, I know about it.

Drift included a computer in their drawing of their school garden and nature in their community:

Susan: ... Okay. Is that a computer? It looks like an iMac.

Drift: Why? 
Susan: Why? It just looks like an iMac, cause it's got the screen with the little stand, and then the keyboard.

Drift: It's different.

Additional experience with computer technology is also revealed by Spiderman, a grade three participant. During their discussion about how their group could gather information on their community-based research questions, the conversation shifts to changing energy sources and how they learn about them:

Spiderman: So many things have changed. Methane, wind power...

Ronaldo: Methane?

Leah: How do you know that?

Spiderman: I watched them. I learned on a channel.

Leah: A channel, what kind of channel might we find out our answers? How could we use that channel?

Spiderman: I forgot the name.

Ronaldo: It might be, the channel called "Olden Days".

Leah: A channel called Olden Days? On TV?

Susan: Should I put that? 
Spiderman: Oh! It's called "Bright Side"

Leah: It's a television show?

Spiderman: It's on everything.

Leah: What do you mean everything? Computers?

Spiderman: Phones, iPad.

Leah: Youtube or website...?

Ronaldo: Youtube.

The excerpts shared here highlight children's personal experience with and knowledge of computer technologies. Likewise and unsurprisingly, children utilize these technologies for a variety of purposes given the multimodal features of modern computer technologies (Hosokawa \& Katsura, 2018; Oliemat et al., 2018; Plowman et al., 2012). For example, computer technologies can be used for the purpose of learning through taking pictures, playing games, watching videos, or engaging in other educational activities (Mertala, 2016; Oliemat et al., 2018). Interestingly, in addition to children noting they play video games or watch videos on these technologies, many children in Empowering Young Citizens referred to learning about nature from computer technologies and how computers can be used to conduct research. It is also important to acknowledge that these participants understood the diversity and complexity of computer technologies as children differentiated between different computer technologies including phones, iPads, and computers. This is evidenced in the conversation between Drift and 
Susan. Though Drift did not explicitly state which technology they drew in their nature drawing, they knew that the technology they were referring to was different than the iMac noted by Susan.

\section{Technology Identity}

Along with sharing the technologies that they knew and used, children expressed confidence in their knowledge of and perceived ability to use digital technologies, even identifying themselves as being technologically savvy. Many young children gain experiences with digital technologies such as computers and touchscreen tablets in their school and home environments (see, for example, McKenney \& Voogt, 2010; Oliemat et al., 2018). This finding was interesting and unanticipated as I did not expect children to delve into this aspect of their identity as it was not an area of focus in the primary study. For example, when preparing to conduct research in the school library, grade two participant Shark Boy exclaimed "I ' $m$ the best at computers." Another example can be seen when grade three participants were engaged in research on waste. While collecting data from books, one of the participants, Clara, stated "I am not like a paper person. I am more more [sic] like an online person."

These examples highlight how technology has become a part of these children's identity. This is understandable as many children now utilize a variety of digital technologies (Oliemat et al., 2018; Otterborn et al., 2018; Slutsky \& DeShetler, 2017; Tena et al., 2019). As children's developing identity is influenced by their experiences, it could be that this aspect of their identity motivates their interest in utilizing technology in their research. The detailed information provided by Ronaldo about their home research on their tablet and their father's computer was particularly insightful as they specifically identified computer technologies accessible to them in 
their home environment. From these experiences, it can be assumed that Ronaldo developed a level of technological competency and though it was not explicitly stated, I imagine that Ronaldo would similarly acknowledge their self to be a technology person as do Shark Boy and Clara.

\section{Closing Thoughts}

It is important to note that the technologies identified here do not necessarily encompass the entirety of all participants' experiences with technology; these technologies are those explicitly identified in conversations with various participants. I would attest that many other children in this project would likely have similar experiences with technology. As noted before, most children have experiences with a multitude of digital technologies (Oliemat et al., 2018; Mantilla \& Edwards, 2019; Slutsky et al., 2019). However, the primary research did not focus on children's use and knowledge of digital technology. Thus, given the opportunity to specifically explore children's technology knowledge and use, it could be found that many more children have experiences with a variety of digital technologies. 


\section{Chapter 5: Children, Technology, and Ecological-based Research}

Children's use of technology to engage with and in nature and ecological research was evident in the data set. Consistent in the literature is the capacity and competence of children as active ecological researchers (see, for example, Barratt Hacking \& Barratt, 2009; Jagger, 2013; Somerville \& Green, 2011). Furthermore, digital technologies have been utilized to support children's ecological research with and in nature (see, for example, Gomes et al., 2016; Kacoroski et al., 2016; Song et al., 2012). As it became apparent that these children had many experiences with digital technologies, it was not surprising that their research would be inclusive of these and additional technologies. However, it is important to highlight that this theme includes both children's planned use and realized use of technology (i.e., the technologies that they wished to use in doing research and those that they actually used in conducting research). While children provided many ideas for utilizing technology to explore aspects of local nature, not all were implemented. Given that the primary data set was not focused on digital technology, I consulted with the primary investigator of this primary research to confirm the participants' experiences with these various technologies.

\section{Computer Technologies}

With respect to the technologies that children suggested utilizing in their research, computer technologies were identified consistently and across all grades. These technologies included computers, laptops, touch-screen tablets, and touch-screen phones. As noted in the previous chapter, computer technologies were an identified source of information for many of the children. Interestingly, though the majority of the groups mentioned the use of a computer 
technology, each grade did have at least one group that did not include computers in their planned or conducted research.

For the children that did suggest utilizing computer technologies, children shared that these technologies could be used in different ways to assist them in conducting their research. For instance, children suggested internet searches on websites such as Google, video searches on YouTube, or using software applications such as Pebble Go or Pebble Go Next to find out information on their ecological research topics. Examples of these are also noted across all three grades. When asked how they could find out information about their topics during the planning stage of their research, grade one participants Spiderman and Cindy both suggested using a computer. Spiderman thought that "we could look on the computer and look [at ] 'how to grow'". Similarly, along with a visit to a local public garden, Cindy proposed viewing videos on YouTube: “... you can go to Marvin Garden and look on YouTube and look for science videos."

In grade two, children expanded on potential sources for their data collection with some children speaking broadly about computer technologies and others identifying newer and specific supports. For example, in their research planning conversation with Susan, Yusuf and Shake identify a number of computer technologies to help them conduct research:

Susan: ... But how can we find out more about that? so you said ask a scientist, which is amazing. What if we don't have a scientist to ask?...

Yusuf: Go to YouTube and type it in.

Susan: What could we do? 
Shake: Go to YouTube.

Yusuf: Go to YouTube and type.

Susan: ...So we've got YouTube, how else could we do research?

Yusuf: We could go to research and type what we want to see.

Susan: How would we do that? What would we use?

Shake: Internet.

Yusuf: Computer.

Similarly, Gila and Ronaldo proposed using an internet search engine (Google) and also different smart devices (Alexa and Cosmo) in their research. Batman and Naja also discussed including computer technologies in their research planning:

Batman: And you can put the, I don't know what it's name, but you can put on the laptop.

Naja: He means the iPad or the laptop.

As with the grade ones and twos, grade three children shared common search engines as potential research tools: 
Mr. X: Yeah, but if I want to look up something, what do I use

to get information?

Rafh: Maybe you can use Google.

Furthermore, grade three children noted specific versions of devices that these searches could be conducted on:

Yusuf: Search on iPad

Robot: We could search on phone. iPhone.

Lexi: iPhone $\mathrm{x}$, iPhone 11 .

Interestingly, potential sources are further diversified as these grade three children went further still to include newer applications to support their research. Lexi and Marta discussed using Pebble Go and Pebble Go Next, an educational software application for touch screen tablets, in their research on how living things adapt to their habitats:

Lexi: We could use Pebble Go or Next Pebble Go.

Marta: It's Pebble Go Next.

Leah: What's that?

Lexi: There's three choices: One is animals, one is science, and what is the other one? 
Leah: This is a computer program?

Yusuf: Yeah, it's about nature.

Initially, participant's suggestions were fairly general. However, though the suggestions of the internet, YouTube, and Google might seem simplistic, each is representative of a specific tool for data collection from secondary sources. The suggestions of the internet and Google refer to collecting information from online search engines, and YouTube is a more specific website that disseminates information through videos. Also, while references to technologies such as Google span different grade levels, other suggestions became more specific in older children as evidenced in Lexi's description of The Pebble Go and Pebble Go Next, the computer or touchscreen tablet software application where children learn about nature.

These uses of this technology have also been observed in other children's ecological research (Gomes et al., 2016; Kacoroski et al., 2016; Song et al., 2012). However, though children suggesting Google was prevalent across all three grades for gathering information, some children had reservations. When a grade one group was discussing how they were going to gather data for their research on worms, Leonardo shared an interesting perspective when another participant, Aadya, shared their experience with Google at home:

Aadya: ... Meghan, I have a computer at my home and we tried to do Google and Google did not work

Meghan: Oh, maybe something was wrong with your computer

Leonardo: Google doesn't know everything 
This statement is of particular interest as it suggests that children recognize that technology has limitations. Even in grade one, Leonardo understood that Google could not answer all of our questions. Thus, since technology such as Google could be perceived as not knowing everything, perhaps this extends to a notion of technology not being inherently helpful or needed to support children's research..

However, what is clear in this research is that children overwhelmingly suggest including different computer technologies in their research projects and many of these tools are suggested to support the collection of data from secondary sources. Furthermore, whether it is the use of a stationary desktop computer, the latest iPhone, or mobile touch-screen tablet, these technologies can be utilized in diverse ways. This is uniquely exemplified by the children's use of Google Maps to explore their local community.

\section{Google Maps}

The children's use of Google Maps, a web mapping service from Google, is noteworthy because of the innovative and interesting way that grade two children utilized it to collect data. One group in each of the two grade two classes was responsible for answering research questions focused on their local environment: 1) Why doesn't our community have many plants? and 2) Why are there so many buildings in our community? Figure 1 displays Dragon Spy’s, Christine's, and Asmi's planning of how they could find answers to those research questions. As seen in their brainstorming, one of the participants suggested utilizing Google Maps to explore the number of buildings there were compared to plants. 


\section{Figure 1}

\section{Group 3 a Environments - Brainstorming Chart}

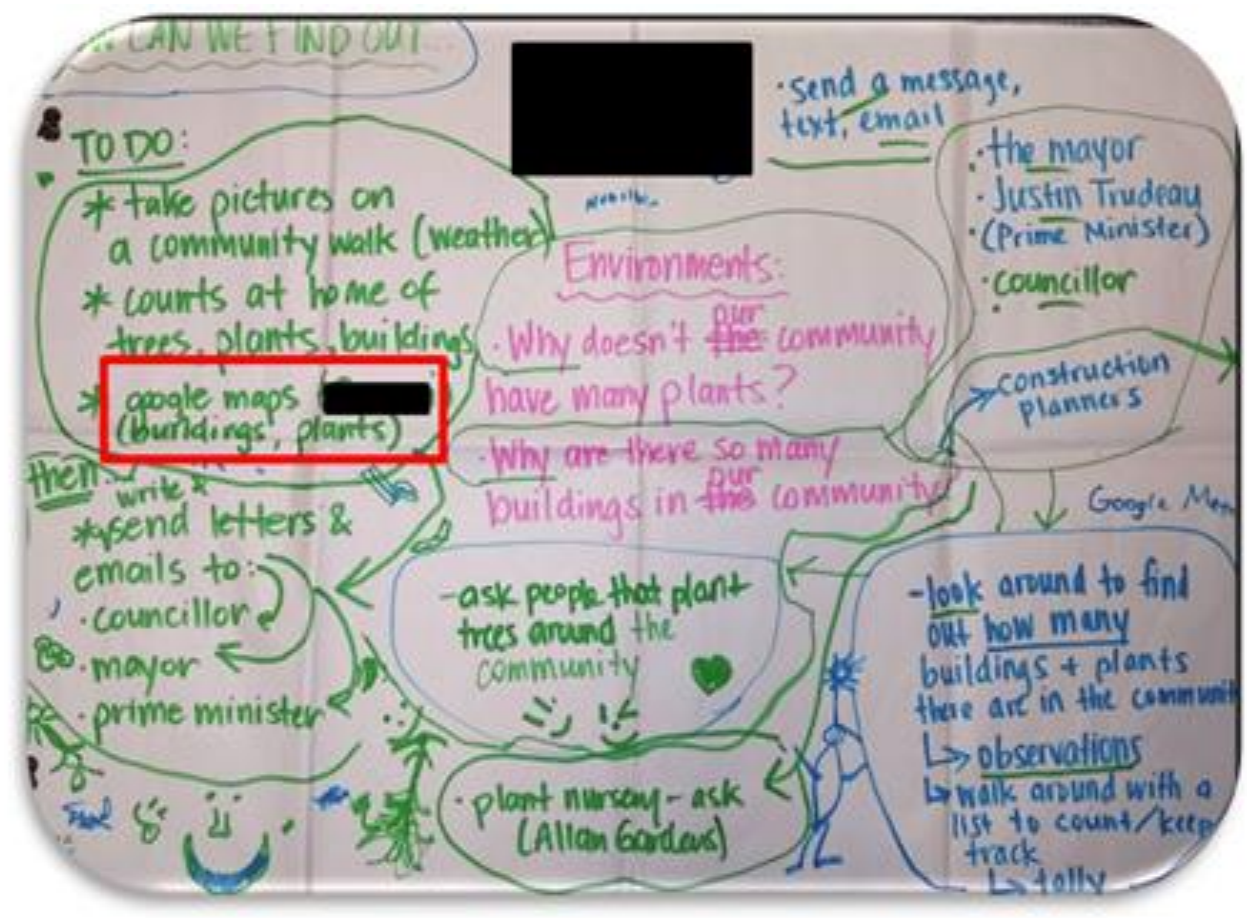

While Google Maps was suggested by a child participant in this class, children in the other group did not make this suggestion. Instead and perhaps inspired by the other class, the use of Google Maps was suggested by an adult researcher:

Meghan: I thought it would be interesting to look at a map. And it's cool that you're doing maps with your teacher right now in class cause I'm going to pull up a map of this neighbourhood and the school on my phone. It's just going to be a map and we're going to put it in the middle and we can all look at it, okay?

The participants gladly accepted this form of exploration and examined the city through the lens of Google Maps. 
Working together with a researcher, children began to make observations of their local environment. An example of what was reviewed can be seen in Figure 2. With Meghan supporting through the use of open ended questions, Zenith and Nat made some observations by examining their environment through the lens of Google Maps. First, Zenith vocalizes one of their findings:

Meghan: So we're going to have a conversation and I'm going to write stuff down. So if we're looking at this map, and Zenith, pretend you want to write a letter to Doug Ford and tell him that there aren't very many plants in your community, looking at this map, is there anything that you notice about this map that you would specifically tell him in that letter that you're writing to him?

Zenith: There's more grass than plants. 


\section{Figure 2}

Group 3 Environments - Screenshot of Google Map

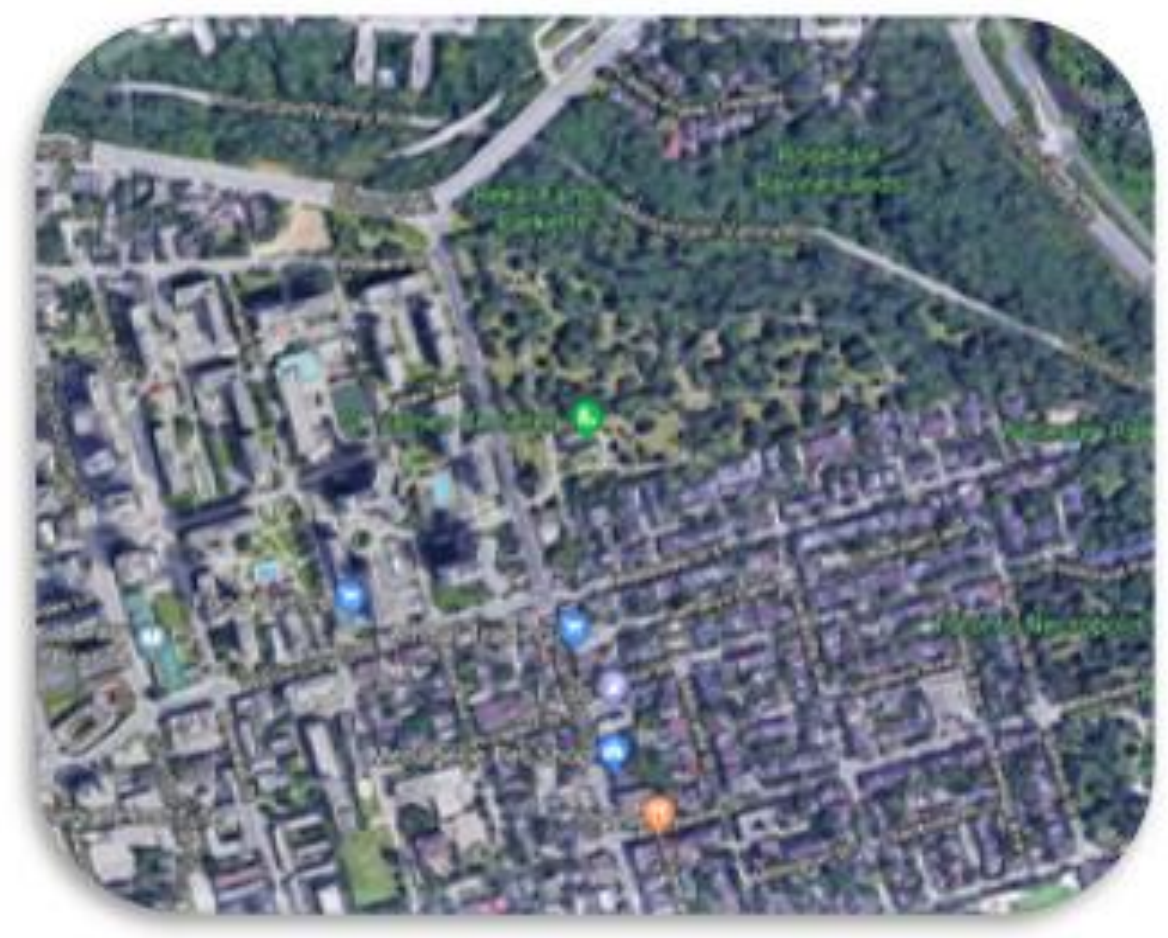

Here, Zenith made an observation between two aspects of nature, grass and plants. However, when asked what they noticed about nature in their community, Nat made another observation:

Meghan: Nat is there anything that you would notice in this map that you think is important for Doug Ford or someone to know what the plants in our community are like? Look at all the trees and stuff over here, and then look at what's around the school.

Nat: All of the community have more buildings and here have more grass. 
In addition to this, Nat also made an inference as to why there were more buildings than plants:

Meghan: Are there any other ideas that you get from looking at the map? Yeah? So look at all of the grass here, but if you ever wanted to go play in a park, that's not really easy to get to.

Nat: They took away the plants and stuff because they want to build buildings.

With respect to Dragon Spy, Christine, and Asmi, their Google Maps exploration acknowledged that there are many buildings in their community and not many trees (see Figure 3).

\section{Figure 3}

Group 3a Environments - Findings Chart

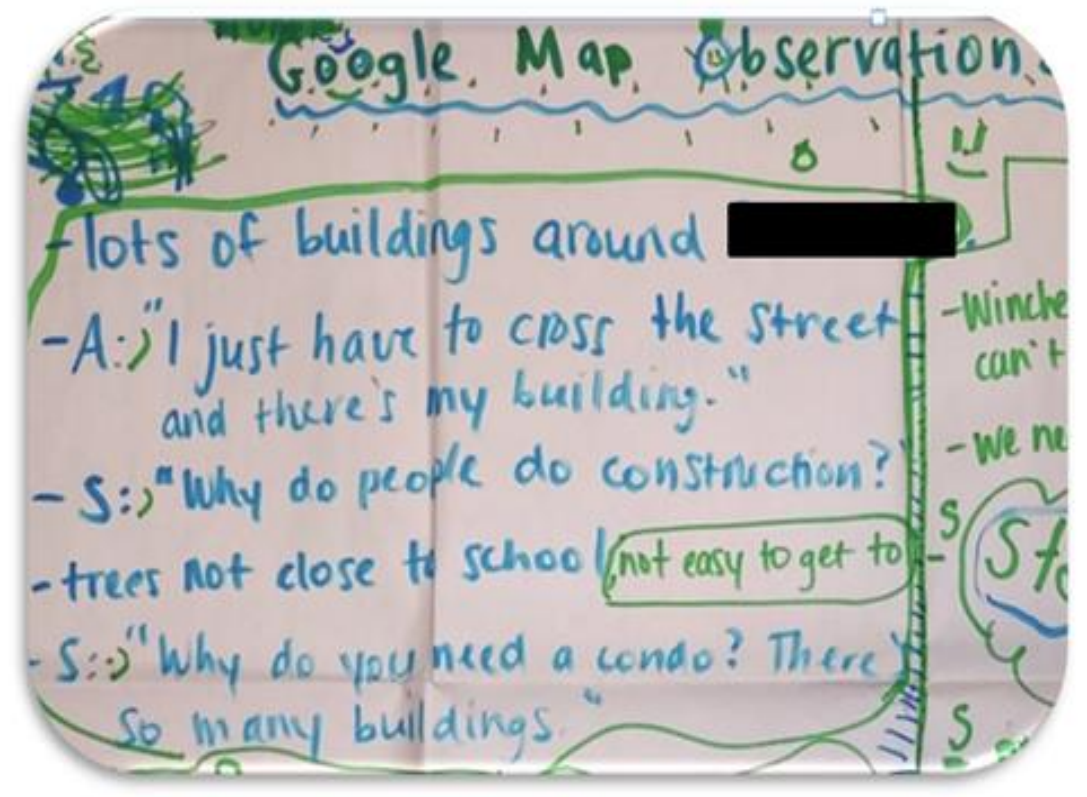


Altogether, the findings from the grade two classes were similar as both acknowledged there were more buildings than nature. These observations also provoked further questions into why there is a need for so many buildings. As seen through Nat's statement, they interpreted there is less nature due to others wanting to build more buildings. Interestingly enough, during this time, there was an active luxury condominium being constructed in between their school and a green space.

Google Maps provided both groups of participants the opportunity to conduct research on their local environment and supported them in making observations in a way that may not have been made available to them otherwise (Perez, 2016; Vanwolleghem et al., 2016). This technology was a great visual aid as children had the opportunity to examine their city at a macro-level, from a bird's eye view, and during the winter season. Given that many plants were covered under snow, it may have been difficult for children to discern how many plants there were in their neighbourhood. Altogether, the use of Google Maps assisted children in their nature-based research and provoked further questioning and critical thought.

\section{Digital Cameras}

While not as versatile or multifaceted as computers or touch-screen tablets, digital cameras were planned for and utilized in conducting research in unique ways. Whereas some children simply put forth the idea of taking pictures to gather data, other children were more specific about how photography was included in their process. For example, during a springtime visit to the school garden with Susan and equipped with cameras, grade one participant Aadya shared that she was "digging for [her] own worm to take a picture [of it ]." Similarly, while planning for data collection and brainstorming ideas of how they could 
find out more information about their topics, grade two participants provided some interesting suggestions that included the use of photography. When discussing how their group might find out more about birds, Naja suggested that, "if your friend is going to Africa, we can tell her, 'Can you take pictures of birds for me?" When planning for their research on different seasons, Shark Boy detailed how one might be able to capture photographs of wild animals in their community:

Shark Boy: And if there's a bear in a den, just bring a flashlight, but don't shine it at the bear. Just be quiet and tiptoe into there and take a picture and then go out quickly so the bear doesn't wake up. Then you could look at the pictures of the bear and then you could see all of it.

Grade three participants also put forth suggestions for the use of a camera in their research on topics related to their school garden and nature in their community. For example, when discussing how their research group could find out about the characteristics of plants, Bloss suggested that they could "put a camera out on our balcony and [watch] the plants grow." Likewise and when discussing how they could gather information on how living things adapt to their habitat, one group of grade three children discussed the use of a camera in data collection. Interestingly, while Marta provided the idea, Yusuf provided insight on how the camera could be placed in the environment: 
Susan: So let's say for example: I've got a plant, and I've got soil. How can I see if they are working together? How could I watch that? What might I set up?

Marta: A camera.

$\cdots$

Leah: And where do you think we could set up a camera?

Yusuf: Oh, we could hide a camera in a tree ... You could cover the camera with a little bit of dirt.

As noted above, children shared a range of ideas about how a camera could be utilized in conducting research. While digital cameras have been used for the purposes of ecological research (see, for example, Green, 2016; Somerville \& Green, 2011; Song et al., 2012; Williams \& Anderson, 2015), it was interesting to see how different children highlighted different aspects of its use. For example, Aadya in grade one had to take action and dig for worms before they could actually take a picture. In grade two, Shark Boy suggested taking great care and using an ample light source when taking pictures. Finally, Yusuf in grade three suggested hiding the camera so as not to draw attention to it. These examples highlight the thought and considerations made by children in their preparation for and actual use of the cameras to capture photographs. Furthermore, their suggestions for their use of the camera suggest a respect for nature. Shark Boy asserted the importance of not bothering the bear should you wish to take its picture and Yusuf thought that a camera should be unobtrusive in nature. Altogether, for these participants, it 
appears that they recognized that taking pictures is no simple task. They could be creative with photography, and there were actions they could take to capture pictures of nature in an effective and respectful manner.

In another interesting instance and in a conversation about finding out about Indigenous histories in the community, Emma, a grade three participant, spoke with Leah about examining older cameras to find out information about First Nations Peoples who lived where their neighbourhood is now located:

Leah: You have an answer down here that I am interested in. Take pictures. What are we going to take pictures of, how is this going to help us find out?

Emma: Maybe if like, you could take pictures or it's a camera and it's First Nations and there is pictures of First Nations and camera. Like an old camera, it was somebody's but they left in on the ground. You found it in the First Nations we could learn more about First Nations by taking those pictures and see about. And also maybe, First Nations were living in the house.

In this dialogue, Emma suggested examining an old camera to gather data from the film that is in that camera. This suggests that Emma understands that the pictures from this hypothetical camera are unique and would provide information about the history of First Nations Peoples. This excerpt from Emma also highlights that if we examine photos taken in a particular 
place and by particular people, we can learn about them, and maybe more importantly, from them.

\section{Technologies for Communication}

Not only did children discuss using technology to collect data, they also suggested and utilized technology for the purpose of communication. Participants suggested a range of ways to use technologies to support recruitment, collection of data, dissemination of findings, and follow-up action and advocacy steps. These included utilizing the school's public address system (announcements) to share messages within their school (e.g., recruitment messages for research surveys and to advocate for how we should treat plants) and emailing members of the government to share research findings and to express the need for the government to take action.

Several research groups across all grades proposed using email in the recruitment of participants in their research and the collection of data. For example, the grade one group that was exploring what people eat from the school garden suggested that people are asked via email what they eat (see Figure 4). 


\section{Figure 4}

Brainstorming Chart for Grade One Group: What Do People Eat from the Garden?

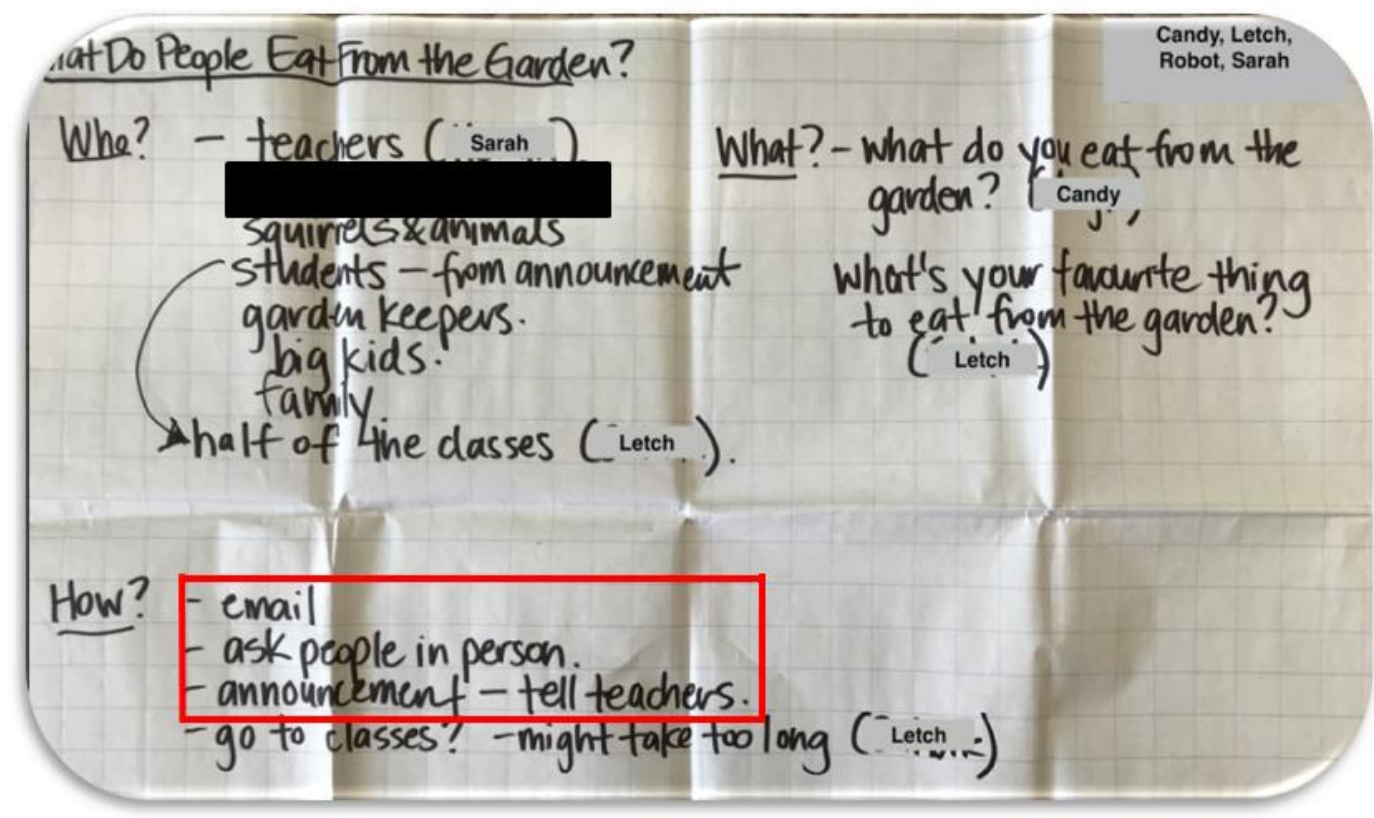

Children in grades one and three suggested using the school's public announcement system for collecting their data (see Figure 4). This is highlighted in the research planning discussion between Susan and a group exploring ecological activism. With respect to recruiting participants for a survey they wanted to conduct in their school, Hyper suggests the use of the school's announcements. Susan responds to Hyper's suggestion:

Susan: Okay, so Hyper's idea is we could have an announcement and Drift said that's like a video but we're talking with our voice if we do that. I am thinking practically. I think an announcement might work well because we do announcements everyday... 
When discussing what they knew and wondered about their school garden and nature in their community, Naja and Hyper, both grade three participants, discussed how nature is treated in their community. Hyper proposes that a school announcement be made:

Naja: I wonder people be nice to the earth?...I wish everyone was nice to the earth.

Hyper: I wish there was an announcement "don't touch other people's plants".

Another particularly interesting way that children proposed to use technology for communication was in the dissemination of their research findings and this was central in both of the grade two groups researching environments in their community. Both groups planned to send emails to various government officials to share their research findings and call for action at different levels of government. These included sending letters to the local city councillor, the mayor, and the prime minister, as evidenced in Figures 5 and 6.

Figure 5, in addition to displaying how children plan to collect data, it also shows their plan for disseminating the findings of their research on their environment. These forms of dissemination include sending letters and emails to various government officials. 


\section{Figure 5}

Brainstorming Chart for Grade Two Group: Environments (Dissemination Suggestions)

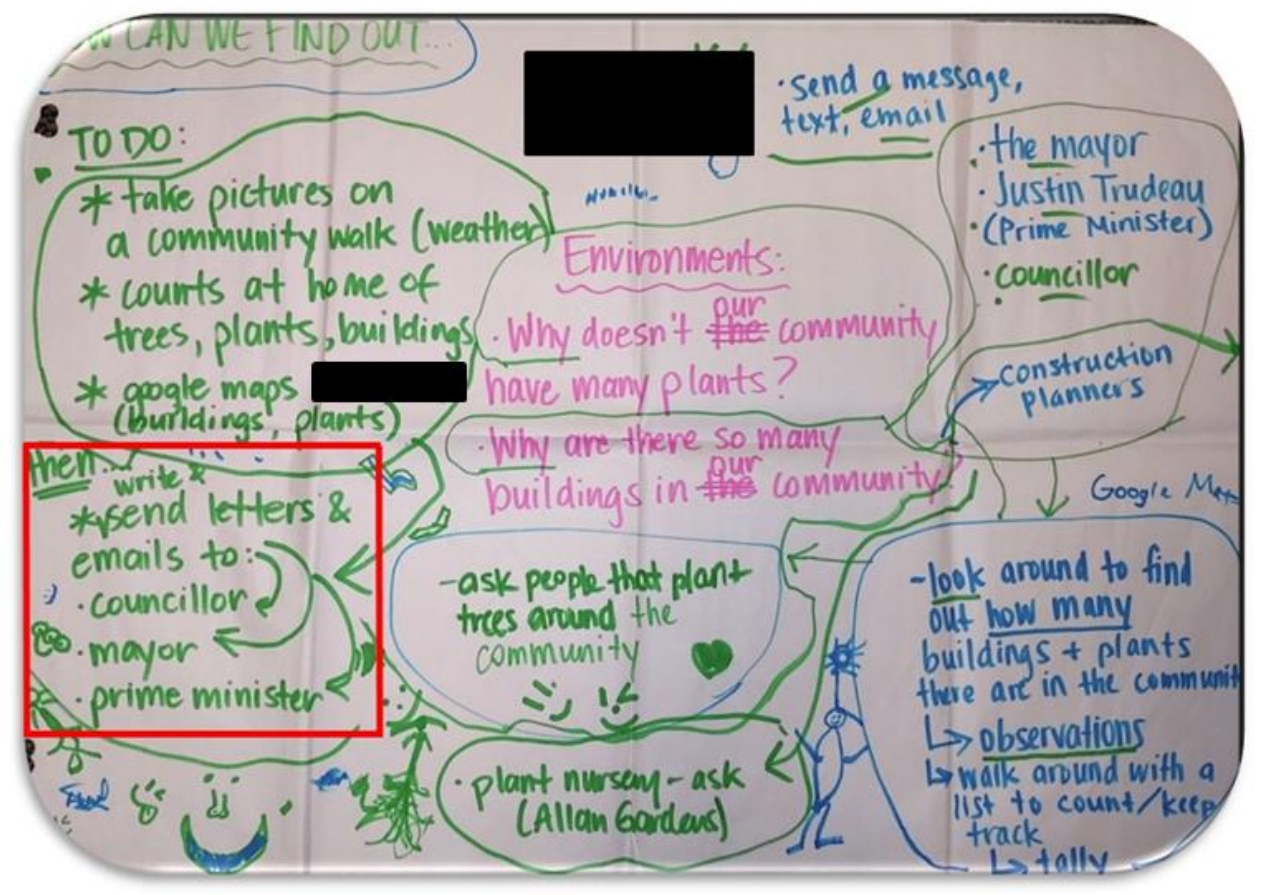

Figure 6 displays the brainstorming ideas of Dragon Spy, Christine, and Asmi as they explored their community environments with Google Maps. Along with the suggestion to email the councillor, calls to action such as stopping the building of condominiums and the cutting of trees were also recommended. 


\section{Figure 6}

\section{Brainstorming Chart for Grade Two Group: Environments}

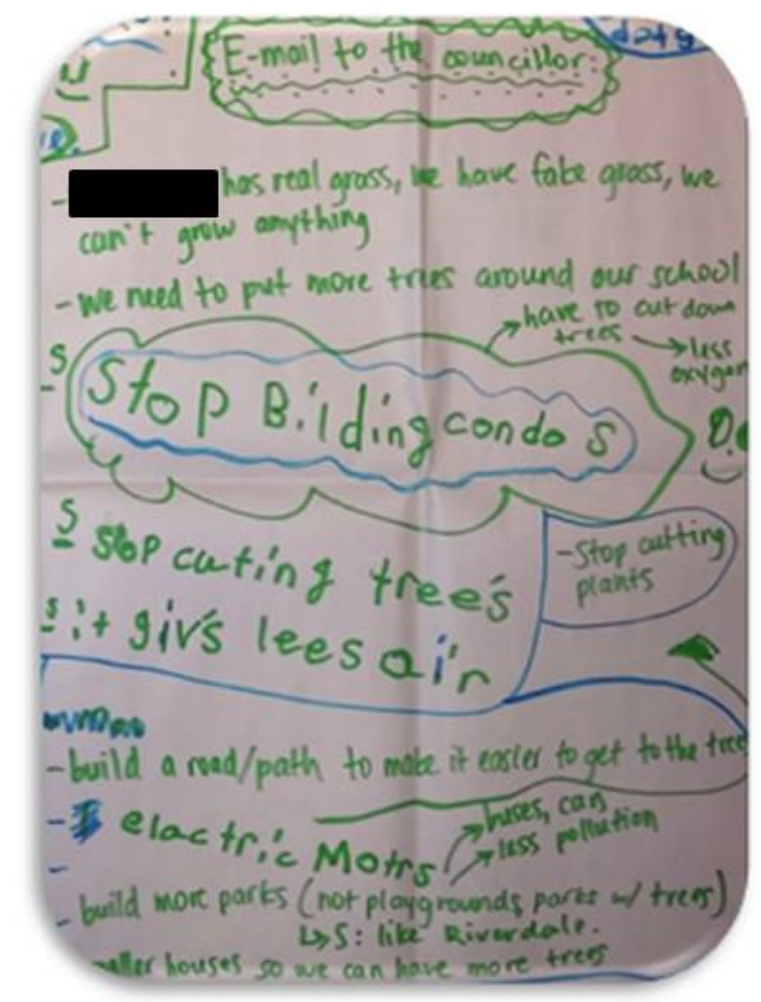

Ahead of sending letters ${ }^{4}$ to government officials, both grade two groups planned for and drafted their correspondences (see Figures 7 and 8). Figure 7 displays a draft of the letter sent to their city councillor. Children made requests of the city that have extended from their research findings that there were not enough trees and too many buildings in their neighbourhood. For example, they suggest the city make a law that prevents the cutting of too many trees and build more parks.

\footnotetext{
${ }^{4}$ It should be noted that printed copies of the grade two children's letters were sent to their city councillor, mayor, and Premier of Ontario. The researchers wanted to get responses for the children and thought that hard copies of the children's letters would be more difficult to ignore than emails; both the mayor's office and the Premier sent replies to the children.
} 


\section{Figure 7}

Draft of Letter to City Councillor from Grade Two Group: Environments

\section{Dear City Councillor,}

- make a law of not cutting too many trees

$\longrightarrow$ we need oxygen

$\longrightarrow$ trees are homes for birds and other animals

$\leftrightarrow$ trees help to give us food

- plant seeds for more trees around the city

and in the community

- build more parks

$\rightarrow$ trees have room to produce more seeds for more trees

Figure 8 shows children's draft of their letter to the Premier of Ontario. Their planning evidences both the children's findings (e.g., there is more grass than plants in their community, part of the community has more plants and the other half has more buildings) as well as their calls for action from the Premier's Office (e.g., add more plants and grass in the community). 


\section{Figure 8}

Draft of Letter to the Premier from Grade Two Group: Environments

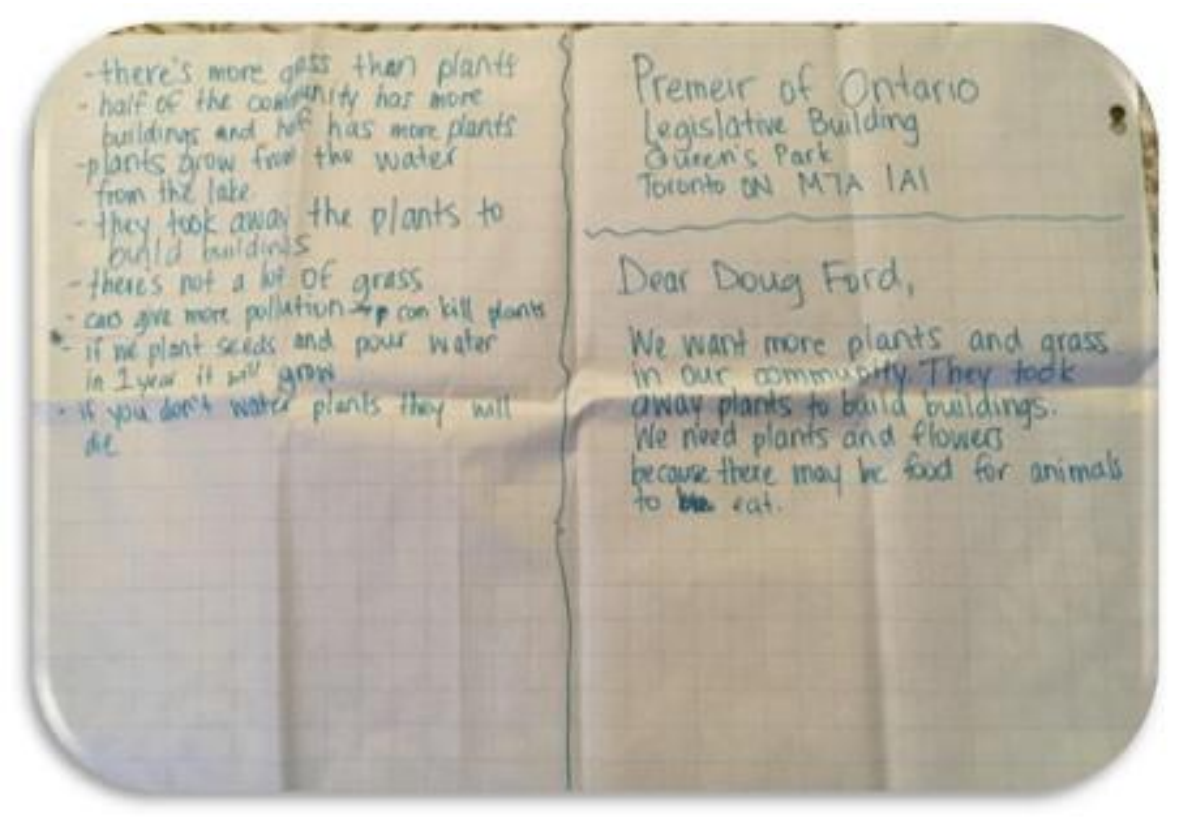

While I anticipated that children would utilize technology in data collection for naturerelated research, I did not anticipate how children might use technology to communicate and disseminate their research to others. However, as seen through these examples, the use of technology also enabled children to share their research in their own community by drafting emails to government officials.

\section{Technology Limitations}

Sometimes when children suggested certain types of technology, it was beyond the scope of what was possible in the research. This is clear, for example, in Emma's suggestion that we find an old camera with film in it to learn about First Nations Peoples. Other examples of 
inclusion of technologies in research that were not feasible or possible were made by grade three participants. First, when asking about how we could find out about what human made and natural features there are in their community, a time machine was suggested:

Leah: What about how do we find out what are the human made and natural features in our community, how would we find that out?

Outou: Make a time machine.

Mr. X[Teacher]: Has anyone thought of more technology aspects, except for time machine?

Outou: I have an idea...it's a machine idea.

Mr. X: Yeah but we're thinking more realistic ideas. So how else do you find information?

While the suggestion given by Outou was quickly deemed unrealistic by their teacher, this perspective was also shared with a fellow class member. As an embodiment of the voice of reason, Rafh details why a time machine is not possible in their exploration of their community:

Rafh: I would say definitely no time machine.

Leah: You don't think we can do the time machine?

Susan: It would be pretty cool but we don't have the technology.

Rafh: I don't think we will have the technology til...3000s or something, we're gonna have time machines. 
Another form of technology that was suggested but not realized was observed in a grade three group that was examining waste. Specifically, they sought to answer two research questions: 1) Where does garbage come from and where does it go? and 2) How can we keep our world healthy? After a researcher discussed with this group that there are applications (apps) which share where certain garbage belongs (e.g., what is recyclable), the children proposed and discussed creating an app to track their school's waste production:

Clara: The school can create an app for itself.

Njura: That's going to be hard

clara: Yeah, but it's still going to succeed I hope.

Michael Jordan: If the app doesn't work what would happen.

Leah: Well this is interesting because we don't necessarily have the skills to create the app...

Leah: Maybe we don't have the technology to create the app right now, but we can still track the garbage in our classroom. And we can still organize and figure out what kind of garbage we are making. And so far you have thought of organizing the garbage: we might find plastics, paper, bottles, food products...

Njura: It will actually take a year to study that complex technology to create an app. 
Leah: I certainly don't know how to create an app yet, maybe...

Clara: I know. I know how to create an app.

Leah: Okay. So before you create an app you need to know what your app is doing. So if we are creating an app that tracks your garbage what type of information would people put into that app? What type of garbage would they say they are creating? How would they do it?

\section{Michael Jordan: We need a professional people who know how to make it. It would be a little complicated for us.}

The children's ideas to include technologies such as a time machine or newly developed software applications were quite creative. A time machine would certainly be helpful in collecting accurate data on what their community used to look like as the information would be gathered from those who actually built, or know about human-made or natural features of their community. With respect to utilizing an application to track their school's garbage and waste, this form of technology use would be an efficient way to gather data from their entire school community, not just information on the waste produced by one classroom. These technologies were not realized for reasons that were discerned by the children and adults. Rafh understood that we do not have the technology to create a time machine at the present time, and Michael Jordan understood that creating a software application is a complicated process and they did not yet possess the necessary skills to do so. 
Interestingly, Clara stated they do know how to create an app. Even so, the creation of an app for their research would have taken a great amount of time and this development would have exceeded the time available to work on the research project. Excluding this limitation of time, perhaps children's ability to develop apps are subject to change as coding is intended to be included into Ontario's 2020 elementary curriculum starting at grade one (Rushowy \& Benzie, 2020). This may be a positive step-forward as children can gain knowledge and experience with utilizing technology to engage in digital creation. As seen through the children's ideas, they embrace creativity and suggest engagements with technology in new and unique ways, especially for use in nature-based and ecological research.

\section{Closing Thoughts}

The Empowering Young Citizens participants that discussed technologies displayed the virtues of digital citizens. That is, these participants put forth responsible, ethical, and appropriate behaviours when utilizing or planning to utilize technology (Johnston et al., 2018). It can be argued that these children put much thought into their decisions to use various technologies and both the participant's suggestions for and utilization of technologies were made with good intentions and reflected their lived experiences. This is clear in Yusuf's and Shark Boy's notion of taking great care when taking pictures of and within nature, through Hyper's use of the announcements as a medium for nature advocacy, and in the grade twos' use of Google Maps to study their local environments.

Interestingly, though technology was sometimes suggested by teachers or researchers, the majority of the technology suggestions were made by the children themselves. Thus, it does not appear that technology was a necessity that was imposed on children's exploration of nature. 
Interestingly, the appearance of technology here almost seems natural. This is not surprising given that many children have experiences with digital technologies in their home and school environment (Mantilla \& Edwards, 2019; Plowman et al., 2012; Slutsky \& DeShetler, 2017; Tena et al., 2019; Wu et al., 2014). Furthermore, these children may not have known a world without these technologies; their lived experiences inherently include technologies. The technologies referenced here were already invented and ubiquitous in this context before these children were born so for these children, perhaps the presence of these technologies is natural. 


\section{Chapter 6: Technology Supporting Children's Connection with Nature}

Digital technology was prevalent in the children's ecological research and many of these children also appeared to be, or had previously been, connected with nature through their use of technology. This aligns with research that children can form personal connections with local

nature as they engage with computer technologies within these environments (Boyce et al., 2014; McClain \& Zimmerman, 2016). Connecting with nature encompasses a variety of factors including cognitive, affective, personal experience, and is subject to social and personal influences (Lumber et al., 2017). Examples of how children connected with nature were articulated throughout the study by the children themselves, through reflections of past experiences, and in the actions they took or suggested in their research.

\section{Children's Connections with Nature through Technology}

The children in this study displayed their connections to nature through their understandings of the natural world and the living and nonliving things within it, gaining knowledge about nature, and expressing feelings of empathy and appreciation, and mindfulness and stewardship of nature. These connections were to some extent supported by their complementary uses of technology and this was apparent across all three grades. During a visit to the school garden with their small group research team, grade one children were examining a rhubarb from their garden and Letch shared his understandings of how plants eat:

Letch: So if they're eating, you pour water and that's how like they drink like us.

Susan: OK 
Letch: And you give them plant foods

Susan: Yeah

Letch: That's how they eat like us

Susan: OK, so we don't actually give... they're collecting sort

of their own kind of plant food. So, these gigantic leaves, they

do help plants to get lots of water. They also get water from

the soil, but what the big leaves do is they help them to

collect sunlight. Then, the plants have this amazing thing

called photosynthesis, it's like food magic

Letch: When I play Plants versus Zombies, the sunflowers collect sun.

Letch's inclusion of technology in his conversation with Susan about plant nutrition was unanticipated and quite unique; I did not even notice this reference of technology until my second read-through of the data set. The technology referenced here is the video game Plants vs. Zombies. While the specific technology that Letch used to play this video game was unclear, Plants vs. Zombies was highlighted as a source of information and a connection to nature. As Letch listened to Susan's discussion of how plants need sunlight, Letch related to the video game they experienced and acknowledged that the sunflowers in their game collected sunlight as well.

This inclusion of technology use provides an interesting opportunity for fostering a connection with nature. In this video game, the goal is to plant a customized garden of flowers 
and other nature-based plants to defend themselves against invading waves of zombies. The sunflowers mentioned by Letch collect sun power and allow the user to increase the number of plants they can utilize against the zombies. Essentially, plants are being utilized to protect nature. This video game could be recognized as a positive influence on children's connection with nature as it allows children to protect nature through the digital experience. Just as Letch collected sun power from their sunflowers, perhaps growing and caring for plants can extend into Letch's worldly actions.

Another example of technology as a means to connect children with nature is seen in grade two. While engaged in a small group discussion about what they knew and wondered about nature, the group discussion led to the topic of garbage being dumped in the ocean and Letch shared what they saw and learned from a video:

Letch: Yeah. Because plastic is getting thrown into the garbage, I watched a video, they made a whale out of plastic and lots of people went to that beach and saw it. And then it looked like a real whale for people and then they stopped throwing garbage. And then I just want to put that episode in now so everyone can see.

Letch noted that the amount of garbage collected in the video was enough to make a life-sized whale and acknowledges that this visual presentation of plastic waste influenced others to stop littering. As it did with Letch, this video, and videos like it, have the potential to influence children's connection with nature through gaining understandings of the natural world and our 
impact on it and motivating positive environmental action. Interestingly, Letch wanted to share this video with their class; Letch found the message being conveyed in this video important and worth sharing to extend its impact. Videos can be influential in children's connection with nature as they can hold important information and have the potential to be shared with others.

Similarly, Rafh, a grade three child, shared videos as a way that he learned about and connected with nature. In his discussion of drawings of the school garden and nature in his community, Rafh shared some ideas about waste and global warming:

Rafh: I watched a video on why we can't just throw garbage into the sun. The answer was it would make the sun more brighter and hotter and make global warming worse.

From the information provided in this video, Rafh recognized that the abundance of garbage produced by people cannot simply be launched into the sun. To Rafh, the major repercussion of this decision would be that it would make global warming worse. The discussion eventually led to imagining what might happen if the Earth was no longer habitable, and whether people could live on the planet Mars and Rafh objected to this possibility:

Rafh: Not really. You know why? Cuz all the wind and the dust storms would wash life away.

What is important to note is that technology was once again utilized as an informative tool that allows us to learn about nature (Gomes et al., 2016; Kacoroski et al., 2016; Song et al., 2012). 
This video appears to have made a lasting impression on Rafh as they referred to this experience in their discussion regarding what they know about nature. Rafh acknowledged global warming to be a problem and that leaving Earth to go to Mars was not a feasible solution. Taken together, it seems that Rafh has a connection to nature through their understanding of the Earth's systems.

\section{Connection with Nature through Action-Oriented Suggestions}

Along with connections of knowledge to nature facilitated by technology, its support of children's connection to nature is also evident in children's action-oriented proposals. These included the planned uses of technology in research that were shared by grade two and three children. This is seen through a proposal from Nat, one of the grade two children that was researching their environment. As noted earlier in this paper, Nat's group used Google Maps to examine their community and its natural and built environments. After observing there were indeed more buildings than plants, Nat made a suggestion for action:

Nat: I watched this program and I got some ideas. We need some seeds, you plant some seeds and pour water and they will grow. Meghan: ...So Nat if we plant seeds and pour water then what?

Nat: In one year it will grow.

Nat's action suggestion motivated by what he had seen in the video would eventually increase the number of plants in the neighbourhood. This suggests that technology supported Nat's understanding of plant growth and connection to nature. 
Another example of how technology can support children's connection with nature is evidenced in the conversation with grade three participants Marta and Yusuf. Their group was exploring the questions: 1) How are living things adapted to their habitats? 2) How do living things work together with non-living things? and 3) Is soil living or non-living? As the group planned for data collection and brainstormed how they could find out answers to their questions, group members suggested making observations and asking scientists. However, another suggestion was made by Marta and then elaborated on by Yusuf:

Susan: So let's say for example: I've got a plant, and I've got soil. How can I see if they are working together? How could I watch that? What might I set up?

Marta: A camera.

$\cdots$

Leah: And where do you think we could set up a camera?

Yusuf: Oh we could hide a camera in a tree.

Yusuf: You could cover the camera with a little bit of dirt.

Though this example was previously highlighted as one of the unique suggestions regarding how a camera could be used, it is also significant in highlighting how children can use technology to connect with nature. While the use of the camera here could have simply been suggested as being utilized to take a picture, Yusuf goes beyond this. Yusuf suggested hiding the camera in a tree and also suggested covering the camera with dirt. After discussing the context of 
these comments with Dr. Jagger, it became clear that the children were discussing how they could observe people and nature without being intrusive. These children understood that the camera could be disruptive to the very nature they were trying to observe and proposed ways to conduct data collection in a respectful way.

Another action-based technology inclusion was suggested when a grade three group planned for ways that they could track the garbage that their school produced through a waste audit. While the children eventually enacted a more direct approach by physically doing a classroom waste sorting and audit, Clara's proposal was noteworthy:

clara: The school can create an app for itself.

Njura: That's going to be hard

Clara: Yeah, but it's still going to succeed I hope.

Clara suggested creating an application that could track the amount and types of waste produced by their school. As discussed earlier, this use of technology was not realized but its suggested use is intriguing. Given that these children's earlier conversations noted that waste was harmful to the environment, Clara wanted to not only to utilize this technology to track waste, but also potentially as a stepping stone to positive environmental actions. Thus, the purpose of this application use seemingly differs from other types of applications that focus solely on the aspect of enhancing environmental and science-based learning (Anderson et al., 2015; Hougham et al., 2015). 


\section{Announcements}

In all years of the study, from grade one through grade three, children expressed that the school's daily announcements could be used in their research. Two groups of grade three children specifically mentioned utilizing the school announcement system to share information about nature and positive environmental action. In the same group as Clara, other participants made suggestions of how they could collect data from their school using announcements:

Michael Jordan: We could do an announcement. Ask Ms. $\mathrm{O}^{5}$ or Mr. D to say in the announcement...

Leah: What would it say in the announcement?

Michael Jordan: "Every classroom check what's in your garbage, compost, and recycling bin." After that we can come to every class in the whole school and we can, everyone will split up and we will have a notebook and have a pen or pencil or marker and write that and what's in there.

While this suggestion is noted to be a possibility, an issue is raised by another participant, Njura:

Njura: Michael Jordan's idea has a problem.

Leah: Okay what's the problem?

Njura: How will we get the allowance (sic) to get the announcement?

\footnotetext{
${ }^{5}$ Ms. O and Mr. D are the school's administrators. Both names are pseudonyms.
} 
Michael Jordan: She will obviously allow us for the pollution thing because she wants our earth to be safe and good. The main announcement has to be about the pollution.

Michael Jordan's justification for why they were doing the announcement extended beyond simply collecting data for their research; the primary reason was to reduce waste and in turn pollution.

A similar mention of the announcement system is made during a small group discussion of grade three children on what they knew and wondered about nature. These children shared many questions, but also expressed some wishes and hopeful thoughts regarding nature as well:

Hyper: I wonder [if] people will help us plant more?

Naja: I wonder if people will be nice in the garden.

Hyper: I wonder if the whole school will help us one day [plant our garden].

Naja: I wonder [if] people be nice to the earth?

Naja: I wish everyone was nice to the earth.

Hyper: I wish there was an announcement "don't touch other people's plants". 
Hyper wanted an announcement reminder for children to not touch other people's plants and, in the context of the conversation about being kind to the garden and the Earth, it appears that Hyper recognizes value and need for protection of nature. In both of these examples, the technology of the school announcement system is not only being utilized simply to communicate messages in an efficient way but it is also being proposed for the purposes of nature advocacy to share important messages with the entirety of the school community. It is possible that as children and adults listen to announcements regarding nature, they may reflect on their own perceptions and experiences with nature. Altogether, the announcement system presents another form of technology that can influence children's connection with nature.

\section{Closing Thoughts}

Altogether, there were multiple examples of children learning about nature, making suggestions that may benefit nature, and that highlighted children's connection with nature. Many of these connections were supported and perhaps even guided by technology. The multifaceted nature of modern computer technologies such as desktop computers, touchscreen tablets, and touchscreen phones, can provide children access to information in a variety of ways (Gomes et al., 2016; Kacoroski et al., 2016; Song et al., 2012). A common way these children learned more about nature was from watching videos on various computer technologies. Through these experiences, children were developing or enhancing their connections with nature.

Furthermore, in order to support nature, children also suggested developing apps or utilizing the school announcement system to relay messages about nature. These examples that were derived from the primary study are but a few ways that technology could be utilized to connect with nature. Other research has identified that technology has been used by children to 
engage with and in nature in new and unique ways (see, for example, Blatt, 2013; Gomes et al., 2016; Green, 2016; Hougham et al., 2018; Kacoroski et al., 2016; Land \& Zimmerman, 2015;

Song et al., 2012). Given the diversity of digital technologies available to children and the unique ways that the children planned for or utilized these technologies, it appears that digital technologies were supportive of these children's connection with nature. 


\section{Chapter 7: Conclusions}

This study examined how children utilize technology to explore nature. Specifically, it asked: 1) What technologies do children use? 2) How can technology help children to connect to nearby nature? and 3) How can technology engage children in nature and ecological research? The experiences of children that participated in nature-based and ecological research in their school and community environments suggest that digital technologies can, and do, support children's engagements with and in nature and connection with nature.

Many children in grades one, two, and three had experiences with and regularly use digital technologies such as televisions, computers, touch-screen phones, and touch-screen tablets. Interestingly, digital technology was prevalent throughout the children's research as they planned for and utilized different technologies to conduct the explorations. For example, computer technologies were suggested to collect data on research topics using internet search engines and websites; Google Maps was utilized to compare the relative ratios of buildings to plants; and email and the school announcement system were suggested to disseminate research findings and advocate for positive environmental action. Though some technologies such as the use of a time machine or the creation of an app were not feasible or impossible, their suggested use indicates that children embrace creativity in their utilization of technology to explore and examine nature.

It was also interesting to see how digital technologies supported children's connection with nature. Many children had experiences of learning about nature through the medium of videos (e.g., how to care for plants, garbage production, global warming). As children learned more about nature, they applied this knowledge to make suggestions that were helpful to nature. 
This was evident in, for example, Nat's suggestion to plant and water seeds in their community when they realized that there were more buildings than plants in their neighbourhood. Children's connection with nature was also seen through their suggestions for how to utilize technology in nature to collect data (e.g., Yusuf's suggested use of a digital camera), and through their suggested use of technologies to share positive messages about nature (e.g., emailing government officials, making school announcements). These examples reinforce the notion that children connecting with nature encompasses cognitive and affective factors as well as personal experience (Lumber et al., 2017).

\section{Limitations}

While the findings of this research provide new insights, there are some limitations that should be accounted for. First, the data is drawn from participants in a single context. As these children live in the same community, there is potential for many of these children to have similar lived experiences with digital technologies. Thus, the findings here are heavily situated. Furthermore, the sample was not consistent as the class assignment of children and teachers changed each school year, some children moved away, and new children joined the school community. While this may have limited this study's ability to track changes over time, it did increase the breadth and diversity of available participants which provided the opportunity for additional insights.

As this study was a secondary data analysis, the findings are interpretations reinforced by the qualitative data set. As the primary study focuses on children's participation in ecological curriculum and research related to their school garden and nearby nature, how children utilize digital technology is not a specific area of focus. There was also no opportunity to collect 
additional data on this more specific research topic from the primary study's participants. Thus, I was limited to interpreting children's noted past experience with technologies, planned use of technologies, and realized uses of technology. However, it is possible that this further strengthens the findings of this study as digital technologies arose organically and were not imposed on children by educators.

Finally, there is potential for bias in my data analysis and interpretations given my perspective on digital technologies. As noted before, my experiences with digital technology vastly outnumber my experiences with and in nature. Thus, my admiration of technology affects how I interpret the data and may limit my analysis. However, through acknowledging this potential bias, I made an effort to remain as objective as possible when reviewing and analyzing the data. I went through the entirety of the data set multiple times, considered children's holistic experience when analyzing their transcripts, and ensured my findings were supported by the data. It was of utmost importance that my findings were not devoid of context.

Additionally, to support my analysis, I engaged with Dr. Jagger in peer debriefing to review my interpretations of the data. As I analyzed the data and produced relevant themes, I conferred with Dr. Jagger to find out whether these themes were accurate and if my evidence supported this. These discussions with Dr. Jagger were beneficial as I found I had to review some of my interpretations as I may have made too many assumptions or I could not strongly support my interpretations with the original data set. Thus, including Dr. Jagger as a peer debriefer helped keep my bias in check and increased the study's validity (Creswell \& Creswell, 2018). 


\section{Implications}

This research can be informative for place-based educators or those who enact a placebased pedagogy. First, educators should know that while the use of technology to explore nature is not mandatory, it should also not be dismissed outright. Educators should recognize that children have unique lived experiences with nature and with digital technologies. As such, when providing opportunities for children to explore nature, educators should consider how technologies can be used to support these engagements. It is however imperative that children are offered the opportunity to make their own suggestions for and decisions about how they explore nature. This can foster a more organic inclusion of technologies in nature explorations rather than more predetermined and close-ended ways. Including technologies for exploration necessitates taking a critical approach in determining how technologies can be utilized in different environmental places (Greenwood \& Hougham, 2015). Taking a critical approach into consideration can provide children with meaningful experiences with and in nature and enhance their nature connectedness.

With respect to children's connection with nature, it is important that educators understand this relationship does not only include their emotional connection and personal experiences with nature, but also includes their knowledge of nature. Digital technologies can be particularly informative for children as they can learn from internet searches and videos on different aspects of nature located in their local and broader environment. This is especially true for children who utilize technology in their ecological and nature-based research. Furthermore, technologies such as the school announcement system can be used by children to share information about nature with their school community. Overall, as children gain and share 
knowledge with different technologies, educators may find these children enhancing their connections with nature.

In thinking of broader recommendations for practice, it may be beneficial to integrate nature-based courses into postsecondary education programs (ex. early childhood education and Bachelor of Education programs) as not all educators are comfortable with or have experience incorporating nature into their pedagogy (Torquati et al., 2017). These courses should be present anyways as it is children's right to have education that fosters their development of respect for the natural environment (United Nations Convention on the Rights of the Child, 1989).These courses may also inform how technology could be incorporated into children's nature exploration and engagement. Furthermore, it is important to note that not all children have the same access to digital technologies. While initiatives such as Ontario's Technology and Learning Fund and the Innovation in Learning Fund did provide funds for technology acquisition and professional development respectively, these funds stopped as of 2017/2018 (People for Education, 2019). Funding for schools to obtain digital technologies and professional development for educators must continue if we are to close this gap in equity.

\section{Future Research}

While this study provides new information on children's use of technology to explore and connect with nature, it was a secondary analysis of an ongoing project with a broader research focus. Thus, more research is necessary to further examine children's use of technology with and in nature. Further empirical research that specifically focuses on children's experience with digital technology with and in nature may provide additional insights. Future research must position children as central in order to capture their thoughts on how they use technology and on 
their perceived connection with nature. With a researcher engaging children as co-researchers, a more thorough understanding of children's experiences can be realized.

As this study explored the context of a school with a garden-based curriculum, it would be interesting to conduct additional research in a learning environment that reflects a typical elementary school in the Greater Toronto Area. Other schools will have access to different natural spaces and technologies, and technologies may be utilized with and in these environments in new and unique ways. Moreover, it may be beneficial for future studies to take a longitudinal approach as notable trends can be tracked over time. To complement this, while it may be difficult, it may prove insightful to have more consistent participants. Finally, future studies should enact qualitative methods as understanding children's experiences with nature and technology requires rich descriptions. Altogether, this study is but a glimpse into how children explore and connect with nature through technology, and further research with children is necessary to better understand their reality. 


\section{Appendix A: Ryerson University Research Ethics Board Approval}

\section{$\begin{array}{ll}\text { Ryerson } & \begin{array}{l}\text { Research } \\ \text { Ethics Board }\end{array}\end{array}$}

To: Michael Agam

Early Childhood Studies

Re: REB 2020-210: From the Ground Up: Children's Experiences of Connecting with Nature through Technology

Date: June 2, 2020

\section{Dear Michael Agam.}

The review of your protocol REB File REB 2020-210 is now complete. The project has been approved for a one year period. Please note that before proceeding with your project, compliance with other required University approvals/certifications, institutional requirements, or governmental authorizations may be required.

This approval may be extended after one year upon request. Please be advised that if the project is not renewed, approval will expire and no more research involving humans may take place. If this is a funded project, access to research funds may also be affected.

Please note that REB approval policies require that you adhere strictly to the protocol as last reviewed by the REB and that any modifications must be approved by the Board before they can be implemented. Adverse or unexpected events must be reported to the REB as soon as possible with an indication from the Principal Investigator as to how, in the view of the Principal Investigator. these events affect the continuation of the protocol.

Finally, if research subjects are in the care of a health facility, at a school, or other institution or community organization, it is the responsibility of the Principal Investigator to ensure that the ethical guidelines and approvals of those facilities or institutions are obtained and filed with the REB prior to the initiation of any research.

Please quote your REB file number (REB 2020-210) on future correspondence.

Congratulations and best of luck in conducting your research.

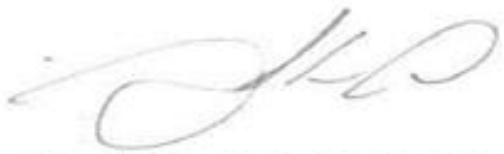

Dr. Asher Alkoby, LL.B., LL.M., S.J.D.

Chair, Ryerson University Research Ethics Board

(416)979-5000 ext. 2491

aalkoby@ryerson.ca

rebchair@ryerson.ca

http://www.ryerson.ca/research 


\section{REFERENCE LIST}

Albanese, P. (2009). Social theories of childhood. In Children in Canada today (pp.18-36). Don Mills, ON.: Oxford University Press.

Anderson, C. L., Miller, B. G., Eitel, K. B., Veletsianos, G., Eitel, J. U. H., \& Hougham, R. J. (2015). Exploring techniques for integrating mobile technology into field-based environmental education. The Electronic Journal of Science Education, 19(6), 1-19

Barratt Hacking, E., Barratt, R., \& Scott, W. (2007). Engaging children: Research issues around participation and environmental learning. Environmental Education Research, 13(4), 529544. doi:10.1080/13504620701600271

Barratt Hacking, E., \& Barratt, R. (2009). Children researching their urban environment: Developing a methodology. Education 3-13: Researching Primary Education: Methods and Issues, 37(4), 371-383. doi:10.1080/03004270903099884

Beery, T., \& Jørgensen, K. A. (2018). Children in nature: Sensory engagement and the experience of biodiversity. Environmental Education Research, 24(1), 13-25. doi:10.1080/13504622.2016.1250149

Bergen, D. (1988). Play as a medium for learning and development: A handbook of theory and practice. Portsmouth, NH: Heinemann.

Berglind, D., \& Tynelius, P. (2018). Objectively measured physical activity patterns, sedentary time and parent-reported screen-time across the day in four-year-old Swedish children. PLoS ONE, 18(1), 69-9. doi:10.1186/s12889-017-4600-5

Blatt, E. (2013). Local tree mapping: A collaborative, place-based activity integrating science, technology, math, and geography. Science Activities, 50(3), 99-109. doi:10.1080/00368121.2013.808165 
Boyce, C. J., Mishra, C., Halverson, K. L., \& Thomas, A. K. (2014). Getting students outside: Using technology as a way to stimulate engagement. Journal of Science Education and Technology, 23(6), 815-826. doi:10.1007/s10956-014-9514-8

Bubikova-Moan, J., Næss Hjetland, H., \& Wollscheid, S. (2019). ECE teachers' views on playbased learning: A systematic review. European Early Childhood Education Research Journal, 27(6), 776-800. doi:10.1080/1350293x.2019.1678717

Cain, V. (2017). From Sesame Street to prime time school television: Educational media in the wake of the Coleman report. History of Education Quarterly, 57(4), 590-601. doi:10.1017/heq.2017.34

Canosa, A., Graham, A., \& Wilson, E. (2018). Reflexivity and ethical mindfulness in participatory research with children: What does it really look like? Childhood, 25(3), 400415. doi:10.1177/0907568218769342

Chatfield, S. L. (2020). Recommendations for secondary analysis of qualitative data. The Qualitative Report, 25(3), 833-842.

Cheng, J. C., \& Monroe, M. C. (2012). Connection to nature: Children's affective attitude toward nature. Environment and Behavior, 44(1), 31-49. doi:10.1177/0013916510385082

Coe, H. (2016). From excuses to encouragements: Confronting and overcoming the barriers to early childhood outdoor learning in Canadian schools. Journal of Childhood Studies (Prospect Bay), 41(1), 5-15. doi:10.18357/jcs.v41i1.15461

Collado, S., Íñiguez-Rueda, L., \& Corraliza, J. A. (2016). Experiencing nature and children’s conceptualizations of the natural world. Children's Geographies, 14(6), 716-730. doi:10.1080/14733285.2016.1190812 
Collingridge, D. S., \& Gantt, E. E. (2008). The quality of qualitative research. American Journal of Medical Quality, 23(5), 389-395

Corsaro, W. A. (2005). The sociology of childhood (2nd ed.). Thousand Oaks, CA: Pine Forge Press.

Crawford, M. R., Holder, M. D., \& O’Connor, B. P. (2017). Using mobile technology to engage children with nature. Environment and Behavior, 49(9), 959-984. doi:10.1177/0013916516673870

Creswell, J. W., \& Creswell, J. D. (2018). Research design: Qualitative, quantitative, and mixed methods approaches $\left(5^{\text {th }}\right.$ ed.) SAGE Publications, Inc.

Dawson, K., \& Beattie, A. E. (2018). Locating the educator in outdoor early childhood education. Australian Journal of Environmental Education, 34(2), 127-142. doi:10.1017/aee.2018.24

Dockett, S. and Perry, B. (2005) "You need to know how to play safe": Children's experiences of starting school. Contemporary Issues in Early Childhood 6(1), 4-18.

Elliot, E., Eycke, K. T., Chan, S., \& Müller, U. (2014). Taking kindergartners outdoors: Documenting their explorations and assessing the impact on their ecological awareness. Children Youth and Environments, 24(2), 102-122. doi:10.7721/chilyoutenvi.24.2.0102

Elliott, V. (2018). Thinking about the coding process in qualitative data analysis. The Qualitative Report, 23(11), 2850-2861.

Foster, J. B. (2016). Nature. Monthly Review, 68(1), 19. doi:10.14452/MR-068-01-2016-05_2

Garriguet, D., Carson, V., Colley, R. C., Janssen, I., Timmons, B. W., \& Tremblay, M. S. (2016). Physical activity and sedentary behaviour of Canadian children aged 3 to 5. Health Reports, 27(9), 14. 
Ghafouri, F. (2014). Close encounters with nature in an urban kindergarten: A study of learners' inquiry and experience. Education 3-13, 42(1), 54-76. doi:10.1080/03004279.2011.642400

Gillies, V., \& Edwards, R. (2005). Secondary analysis in exploring family and social change: Addressing the issue of context. Forum Qualitative Social Research Sozialforschung, 6(1), 115

Glaser, B. G., \& Strauss, A. L. (1967). The discovery of grounded theory. New York: Aldine de Gruyter.

Golinkoff, R. M., Hirsh-Pasek, K., \& Singer, D. G. (2006). Play = learning: How play motivates and enhances children's cognitive and social-emotional growth. New York: Oxford University Press. doi:10.1093/acprof:oso/9780195304381.001.0001

Gomes, C. A., Novais, A., \& Abrantes, I. (2016). Exploring the vineyard cycle: Mobile technology in non-formal environmental education settings. Paper presented at the International Symposium on Computers in Education (SIIE), 1-6. doi:10.1109/SIIE.2016.7751850

Goode, J. A., Fomby, P., Mollborn, S., \& Limburg, A. (2019). Children's technology time in two US cohorts. Child Indicators Research, 13(3), 1107 - 1132. doi:10.1007/s12187-019-09675-X

Green, C. (2013). A sense of autonomy in young children's special places. International Journal of Early Childhood Environmental Education, 1(1), 8.

Green, C. (2016). Sensory tours as a method for engaging children as active researchers: Exploring the use of wearable cameras in early childhood research. International Journal of Early Childhood, 48(3), 277-294. doi:10.1007/s13158-016-0173-1 
Greenwood, D. A., \& Hougham, R. J. (2015). Mitigation and adaptation: Critical perspectives toward digital technologies in place-conscious environmental education. Policy Futures in Education, 13(1), 97-116. doi:10.1177/1478210314566732

Hammarsten, M., Askerlund, P., Almers, E., Avery, H., \& Samuelsson, T. (2019). Developing ecological literacy in a forest garden: Children's perspectives. Journal of Adventure Education and Outdoor Learning, 19(3), 227-241. doi:10.1080/14729679.2018.1517371

Hammersley, M. (2010). Can we re-use qualitative data via secondary analysis? Notes on some terminological and substantive issues. Sociological Research Online, 15(1), 1-7.

Hatzigianni, M. (2018). Transforming early childhood experiences with digital technologies. Global Studies of Childhood, 8(2), 173-183. doi:10.1177/2043610617734987

Heaton, J. (2008). Secondary analysis of qualitative data: An overview. Historical Social Research, 33 (3-125), 33-45.

Hinkley, T., Brown, H., Carson, V., \& Teychenne, M. (2018). Cross sectional associations of screen time and outdoor play with social skills in preschool children. PLoS One, 13(4), e0193700. doi:10.1371/journal.pone.0193700

Holloway, P., \& Mahan, C. (2012). Enhance nature exploration with technology. Science Scope, 35(9), 23-28.

Horgan, D. (2017). Child participatory research methods: Attempts to go 'deeper'. Childhood, 24(2), 245-259. doi:10.1177/0907568216647787

Hosokawa, R., \& Katsura, T. (2018). Association between mobile technology use and child adjustment in early elementary school age. PloS One, 13(7), 1-17. doi:10.1371/journal.pone.0199959 
Hougham, R. J., Eitel, K. C. B., \& Miller, B. G. (2015). Technology-enriched STEM investigations of place: Using technology to extend the senses and build connections to and between places in science education. Journal of Geoscience Education, 63(2), 90-97. doi:10.5408/12-399.1

Hougham, R. J., Nutter, M., \& Graham, C. (2018). Bridging natural and digital domains: Attitudes, confidence, and interest in using technology to learn outdoors. The Journal of Experiential Education, 41(2), 154-169. doi:10.1177/1053825917751203

Hung, C., Sun, J. C., \& Yu, P. (2015). The benefits of a challenge: Student motivation and flow experience in tablet-PC-game-based learning. Interactive Learning Environments, 23(2), 172190. doi:10.1080/10494820.2014.997248

Iorio, J., Hamm, C., Parnell, W., \& Quintero, E. (2017). Place, Matters of Concern, and Pedagogy: Making Impactful Connections with Our Planet. Journal of Early Childhood Teacher Education, 38(2), 121-135.

Irwin, S. (2013). Qualitative secondary data analysis: Ethics, epistemology and context. Progress in Development Studies, 13(4), 295-306.

Irwin, S., Bornat, J., \& Winterton, M. (2012). Timescapes secondary analysis: Comparison, context and working across data sets. Qualitative Research, 12(1), 66-80.

Jagger, S. L. (2013). "This is more like home": Knowing nature through community mapping. Canadian Journal of Environmental Education, 18, 173-189.

James, A. (2013). Seeking the analytic imagination: Reflections on the process of interpreting qualitative data. Qualitative Research, 13(5), 562-577 
Johnston, K., Highfield, K., \& Hadley, F. (2018). Supporting young children as digital citizens: The importance of shared understandings of technology to support integration in play-based learning. British Journal of Educational Technology, 49(5), 896-910. doi:10.1111/bjet.12664

Johnston, M.P. (2014). Secondary data analysis: A method of which the time has come. Qualitative and Quantitative Methods in Libraries, 3(3), 619-626.

Kacoroski, J., Liddicoat, K. R., \& Kerlin, S. (2016). Children's use of iPads in outdoor environmental education programs. Applied Environmental Education \& Communication, 15(4), 301-311. doi:10.1080/1533015X.2016.1237903

Kahn, P. H., Jr., \& Weiss, T. (2017). The importance of children interacting with big nature. Children, Youth and Environments, 27(2), 7-24. doi:10.7721/chilyoutenvi.27.2.0007

Kellert, S.R. (2009). Reflections on children's experience of nature. $C \& N N$ [Children \& Nature Network] Leadership Writing Series, 1(2), 1-5. Retrieved July 12, 2020, from: https://www.childrenandnature.org/wp-content/uploads/2015/04/LWS_Vol1_02.pdf

Kellett, M., Robinson, C., \& Burr, R. (2004). Images of childhood. In S. Fraser, V. Lewis, S. Ding, M. Kellett, \& C. Robinson (Eds.), Doing research with children and young people (pp. 27-42). Thousand Oaks, CA: Sage.

Kemmis, S., \& McTaggart, R. (2005). Participatory action research. In N. Denzin \& Y. Lincoln (Eds.), Handbook of qualitative research (3rd ed., pp. 559-603). Thousand Oaks, CA: Sage.

Keniger, L., Gaston, K., Irvine, K., \& Fuller, R. (2013). What are the benefits of interacting with nature? International Journal of Environmental Research and Public Health, 10(3), 913-935. doi:10.3390/ijerph10030913

Kirby, P. (2002). Involving young people in research. In B. Franklin (Ed.), The new handbook of children's rights: Comparative policy and practice (pp. 268-284). New York: Routledge. 
Land, S. M., \& Zimmerman, H. T. (2015). Socio-technical dimensions of an outdoor mobile learning environment: A three-phase design-based research investigation. Educational Technology Research and Development, 63(2), 229-255. doi:10.1007/s11423-015-9369-6

Langhout, R. D., \& Thomas, E. (2010). Imagining participatory action research in collaboration with children: An introduction. American Journal of Community Psychology, 46(1-2), 60-66.

Leech, N. \& Onwuegbuzie, S. (2007) An array of qualitative data analysis tools: A call for data analysis triangulation. School Psychology Quarterly, 22(4), 557-584.

Lumber, R., Richardson, M., \& Sheffield, D. (2017). Beyond knowing nature: Contact, emotion, compassion, meaning, and beauty are pathways to nature connection. PloS One, 12(5), 1-24. doi:10.1371/journal.pone.0177186

Lundy, L., McEvoy, L., \& Byrne, B. (2011). Working with young children as co-researchers: An approach informed by the United Nations Convention on the Rights of the Child. Early Education and Development, 22(5), 714-736.

MacQuarrie, S., Nugent, C., \& Warden, C. (2015). Learning with nature and learning from others: Nature as setting and resource for early childhood education. Journal of Adventure Education and Outdoor Learning, 15(1), 1-23. doi:10.1080/14729679.2013.841095

Mantilla, A., \& Edwards, S. (2019). Digital technology use by and with young children: A systematic review for the statement on young children and digital technologies. Australasian Journal of Early Childhood, 44(2), 182-195. doi:10.1177/1836939119832744

Mayall, B. (2002). Toward a sociology of childhood: Thinking from children's lives. Philadelphia, PA: Open University Press.

McClain, L. R., \& Zimmerman, H. T. (2016). Technology-mediated engagement with nature: Sensory and social engagement with the outdoors supported through an e-trailguide. 
International Journal of Science Education, Part B, 6(4), 385-399.

doi:10.1080/21548455.2016.1148827

McKenney, S., \& Voogt, J. (2010). Technology and young children: How 4-7 year olds perceive their own use of computers. Computers in Human Behavior, 26(4), 656-664.

doi:10.1016/j.chb.2010.01.002

Mertala, P. (2016). Fun and games - Finnish children's ideas for the use of digital media in preschool. Nordic Journal of Digital Literacy, 10(4), 207-226. doi:10.18261/issn.1891-943x2016-04-01

Mertala, P. (2019). Digital technologies in early childhood education - a frame analysis of preservice teachers' perceptions. Early Child Development and Care, 189(8), 1228-1241. doi:10.1080/03004430.2017.1372756

Miller, T. (2018). Developing numeracy skills using interactive technology in a play-based learning environment. International Journal of STEM Education, 5(1), 1-11. doi:10.1186/s40594-018-0135-2

Mordock, K., \& Krasny, M. E. (2001). Participatory action research: A theoretical and practical framework for EE. Journal of Environmental Education, 32(3), 15-20.

Nazir, J., \& Pedretti, E. (2016). Educators' perceptions of bringing students to environmental consciousness through engaging outdoor experiences. Environmental Education Research, 22(2), 288-304. doi:10.1080/13504622.2014.996208

Neuman, W.L. (2004). Analysis of qualitative data. In Basics of social research: Qualitative and quantitative approaches (pp. 318-334). Boston, MA: Pearson.

Nxumalo, F. (2018). Stories for living on a damaged planet: Environmental education in a preschool classroom. Journal of Early Childhood Research, 16(2), 148-159. 
Oliemat, E., Ihmeideh, F., \& Alkhawaldeh, M. (2018). The use of touch-screen tablets in early childhood: Children's knowledge, skills, and attitudes towards tablet technology. Children and Youth Services Review, 88, 591-597. doi:10.1016/j.childyouth.2018.03.028

Otterborn, A., Schönborn, K., Hultén, M. (2018). Surveying preschool teachers' use of digital tablets: General and technology education related findings. International Journal of Technology and Design Education, 29(4), 717-737. doi:10.1007/s10798-018-9469-9

Pascal, C., \& Bertram, T. (2009). Listening to young citizens: The struggle to make real a participatory paradigm in research with young children. European Early Childhood Education Research Journal, 17(2), 249-262.

Perez, S. (2016, August 3). Google launches a kids' map app that lets them explore 3D imagery of the Himalayas. Techcrunch. http://ezproxy.lib.ryerson.ca/login?url=https://searchproquest-com.ezproxy.lib.ryerson.ca/docview/1808478905?accountid=13631

People for Education (2019). Connecting to Success: Technology in Ontario Schools. Toronto, ON: People for Education.

Pienta, A. M., O'Rourke, J. M., \& Franks, M. M. (2011). Getting started: Working with secondary data. In M. B. Donnellan, R. E. Lucas, \& K. H. Trzesniewski (Eds.), Secondary data analysis: An introduction for psychologists (pp. 13-25). Washington, DC: American Psychological Association. doi:10.1037/12350-000

Plowman, L., Stephen, C., \& McPake, J. (2010). Supporting young children's learning with technology at home and in preschool. Research Papers in Education, 25(1), 93-113. doi:10.1080/02671520802584061 
Plowman, L., Stevenson, O., Stephen, C., \& McPake, J. (2012). Preschool children's learning with technology at home. Computers \& Education, 59(1), 30-37. doi:10.1016/j.compedu.2011.11.014

Przybylski, A. K., \& Weinstein, N. (2019). Digital screen time limits and young children's psychological well-being: Evidence from a population-based study. Child Development, 90(1), e56-e65. doi:10.1111/cdev.13007

Pyle, A., \& Alaca, B. (2018). Kindergarten children's perspectives on play and learning. Early Child Development and Care, 188(8), 1063-1075. doi:10.1080/03004430.2016.1245190

Pyle, A., \& Bigelow, A. (2015). Play in kindergarten: An interview and observational study in three Canadian classrooms. Early Childhood Education Journal, 43(5), 385-393.

Quennerstedt, A., \& Quennerstedt, M. (2014). Researching children's rights in education: Sociology of childhood encountering educational theory. British Journal of Sociology of Education, 35(1), 115-132. doi:10.1080/01425692.2013.783962

Raffety, E. L. (2015). Minimizing social distance: Participatory research with children. Childhood, 22(3), 409-422. doi:10.1177/0907568214548283

Reeves, J. L., Gunter, G. A., \& Lacey, C. (2017). Mobile learning in pre-kindergarten: Using student feedback to inform practice. Journal of Educational Technology \& Society, 20(1), 3744.

Rios, C., \& Menezes, I. (2017). 'I saw a magical garden with flowers that people could not damage!' Children's visions of nature and of learning about nature in and out of school. Environmental Education Research, 23(10), 1402-1413. doi:10.1080/13504622.2017.1325450 
Robottom, I., \& Sauvé, L. (2003). Reflecting on participatory research in environmental education: Some issues for methodology. Canadian Journal of Environmental Education, $8(1), 11-128$.

Roschelle, J. M., Pea, R. D., Hoadley, C. M., Gordin, D. N., \& Means, B. M. (2000). Changing how and what children learn in school with computer-based technologies. The Future of Children, 10(2), 76-101. doi:10.2307/1602690

Ruggiano, N., \& Perry, T. E. (2019). Conducting secondary analysis of qualitative data: Should we, can we, and how? Qualitative Social Work, 18(1), 81-97.

Rushowy, K., \& Benzie, R. (2020, June 23). New Ontario elementary math curriculum to include coding starting in Grade 1. Retrieved July 02, 2020, from https://www.thestar.com/politics/provincial/2020/06/23/new-ontario-elementary-mathcurriculum-to-include-coding-starting-in-grade-1.html

Saldaña, J. (2009). The coding manual for qualitative researchers. London, UK: SAGE.

Shamrova, D. P., \& Cummings, C. E. (2017). Participatory action research (PAR) with children and youth: An integrative review of methodology and PAR outcomes for participants, organizations, and communities. Children and Youth Services Review, 81, 400-412. doi:10.1016/j.childyouth.2017.08.022

Slutsky, R., \& DeShetler, L.M. (2017). How technology is transforming the ways in which children play. Early Child Development and Care, 187(7), 1138 - 1146.

Slutsky, R., Kragh-Müller, G., Rentzou, K., Tuul, M., Gol Guven, M., Foerch, D., \& Paz-Albo, J. (2019). A cross-cultural study on technology use in preschool classrooms: Early childhood teacher's preferences, time-use, impact and association with children's play. Early Child Development and Care, 1-13. doi:10.1080/03004430.2019.1645135 
Sobel, D. (2004). Place-based education: Connecting classrooms and communities. Great Barrington, MA: The Orion Society.

Somerville, M., \& Green, M. (2011). A pedagogy of “organized chaos”: Ecological learning in primary schools. Children, Youth and Environments, 21(1), 14-34.

Song, Y., Wong, L., \& Looi, C. (2012). Fostering personalized learning in science inquiry supported by mobile technologies. Educational Technology Research and Development, 60(4), 679-701. doi:10.1007/s11423-012-9245-6

Tena, R. R., Gutiérrez, M. P., \& Cejudo, M. D. C. L. (2019). Technology use habits of children under six years of age at home. Ensaio: Avaliação e Políticas Públicas Em Educação, 27(103), 340-362. doi:10.1590/s0104-40362019002701752

Tillmann, S., Clark, A. F., \& Gilliland, J. A. (2018). Children and nature: Linking accessibility of natural environments and children's health-related quality of life. International Journal of Environmental Research and Public Health, 15(6), 1-15. doi:10.3390/ijerph15061072

Torquati J., Leeper-Miller J., Hamel E., Hong S., Sarver S., \& Rupiper M. (2017). "I Have a hippopotamus!": Preparing effective early childhood environmental educators. The New Educator, 13(3), 207-233.

Tracy, S. J. (2010). Qualitative quality: Eight "Big-tent" criteria for excellent qualitative research. Qualitative Inquiry, 16(10), 837-851.

United Nations Convention on the Rights of the Child, November 20, 1989, http://www.ohchr.org/en/professionalinterest/pages/crc.aspx.

United Nations. (2005). Convention on the rights of the child: General comment no. 7. Implementing child rights in early childhood. Geneva, Switzerland: Author. 
Vanwolleghem, G., Ghekiere, A., Cardon, G., De Bourdeaudhuij, I., D’Haese, S., Geremia, C. M., Lenoir, M., Sallis, J.F., Verhoeven, H., \& Van Dyck, D. (2016). Using an audit tool (MAPS global) to assess the characteristics of the physical environment related to walking for transport in youth: Reliability of Belgian data. International Journal of Health Geographics, 15(1), 41-11. doi:10.1186/s12942-016-0069-1

Venetsanou, F., Kambas, A., Gourgoulis, V., \& Yannakoulia, M. (2019). Physical activity in preschool children: Trends over time and associations with body mass index and screen time. Annals of Human Biology, 46(5), 393-399. doi:10.1080/03014460.2019.1659414

Williams, D., \& Anderson, J. (2015). Tongue-tied no more: Diversity pedagogy and sense of place in the learning gardens. Canadian Journal of Environmental Education, 20, 25-45.

Willis, J., Weiser, B., \& Kirkwood, D. (2014). Bridging the gap: Meeting the needs of early childhood students by integrating technology and environmental education. International Journal of Early Childhood Environmental Education, 2(1), 140-155.

Wu, C. S. T., Fowler, C., Lam, W. Y. Y., Wong, H. T., Wong, C. H. M., \& Yuen Loke, A. (2014). Parenting approaches and digital technology use of preschool age children in a Chinese community. Italian Journal of Pediatrics,40(1), 1-8. doi:10.1186/1824-7288-40-44

Yelland, N., \& Gilbert, C. (2018). Transformative technologies and play in the early years: Using tablets for new learning. Global Studies of Childhood, 8(2), 152-161. doi:10.1177/2043610617734985

Yilmaz, K. (2013) Comparison of Quantitative and Qualitative Research Traditions: Epistemological, theoretical, and methodological differences. European Journal of Education, 48(2), 311-325. 